\title{
Influences of Local and Remote Conditions on Tropical Precipitation and Its Response to Climate Change ${ }^{\mathscr{a}}$
}

\author{
MARION SAINT-LU \\ University of Exeter, Exeter, United Kingdom \\ ROBIN CHADWICK \\ Met Office Hadley Centre, and Global Systems Institute, University of Exeter, Exeter, United Kingdom \\ F. Hugo Lambert And MatThew Collins \\ University of Exeter, Exeter, United Kingdom \\ IAN BOUTLE AND MichaEL WhitALL \\ Met Office, Exeter, United Kingdom \\ CHIMENE DALEU \\ University of Reading, Reading, United Kingdom
}

(Manuscript received 19 June 2019, in final form 16 January 2020)

\begin{abstract}
By comparing a single-column model (SCM) with closely related general circulation models (GCMs), precipitation changes that can be diagnosed from local changes in surface temperature $\left(T_{S}\right)$ and relative humidity $\left(\mathrm{RH}_{S}\right)$ are separated from more complex responses. In the SCM setup, the large-scale tropical circulation is parameterized to respond to the surface temperature departure from a prescribed environment, following the weak temperature gradient (WTG) approximation and using the damped gravity wave (DGW) parameterization. The SCM is also forced with moisture variations. First, it is found that most of the presentday mean tropical rainfall and circulation pattern is associated with $T_{S}$ and $\mathrm{RH}_{S}$ patterns. Climate change experiments with the SCM are performed, imposing separately surface warming and $\mathrm{CO}_{2}$ increase. The rainfall responses to future changes in sea surface temperature patterns and plant physiology are successfully reproduced, suggesting that these are direct responses to local changes in convective instability. However, the SCM increases oceanic rainfall too much, and fails to reproduce the land rainfall decrease, both of which are associated with uniform ocean warming. It is argued that remote atmospheric teleconnections play a crucial role in both weakening the atmospheric overturning circulation and constraining precipitation changes. Results suggest that the overturning circulation weakens, both as a direct local response to increased $\mathrm{CO}_{2}$ and in response to energy-imbalance driven exchanges between ascent and descent regions.
\end{abstract}

Supplemental information related to this paper is available at the Journals Online website: https://doi.org/10.1175/JCLI-D-190450.s1.

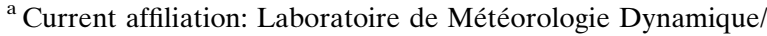
Institut Pierre Simon Laplace, Sorbonne Université, Université Pierre et Marie Curie, Paris, France.
}

Corresponding author: Marion Saint-Lu, marion.saint-lu@lmd. jussieu.fr

\section{Introduction}

Uncertainty remains in how tropical rainfall will change in the future, particularly at regional scales. Previous studies have shown that the mean future changes in tropical rainfall mainly consist in shifts, which over the oceans are mainly driven by changes in the mean sea surface temperature (SST) pattern, following the so-called "warmer-get-wetter" mechanism (Xie et al. 2010; Ma and Xie 2013; Chadwick et al. 2014; Kent et al.2015). However, rainfall changes over land seem to 
be driven by more complex combinations of different aspects of the $\mathrm{CO}_{2}$ forcing, including changes in the plant physiology, in the atmospheric radiative cooling, or in the mean ocean warming (e.g., Betts et al. 2004; Giannini 2010; Cao et al. 2012; Chadwick et al. 2017). Understanding tropical rainfall changes under global warming would help to improve future projections that still exhibit strong disagreement and better inform climate adaptation policy (Knutti and Sedláček 2013; Collins et al. 2013; Shepherd 2014; Kent et al. 2015; Oueslati et al. 2016; Long et al. 2016).

Based on the observation that horizontal gradients of free-tropospheric temperatures are weak in the tropics, the so-called weak temperature gradient (WTG) approximation suggests that convective instability is largely driven by spatial variations in surface temperature and moisture (Sobel and Bretherton 2000; Sobel et al. 2001). The influence of free-tropospheric moisture gradients on precipitation patterns is not ruled out by the WTG approximation.

Based on this theory, Lambert et al. (2017) and Todd et al. (2018) have diagnosed tropical rainfall patterns and shifts from two surface observable variables, surface temperature $\left(T_{S}\right)$ and near-surface relative humidity $\left(\mathrm{RH}_{S}\right)$, with the idea that precipitation falls in the highest $T_{S}$ and $\mathrm{RH}_{S}$ regions. This view is based on the argument (from convective quasi-equilibrium and WTG approximation) that tropical precipitation is a function of $T_{S}$ and $\mathrm{RH}_{S}$ and that rainfall shifts can be diagnosed from the combination of $T_{S}$ shifts and $\mathrm{RH}_{S}$ shifts.

The general aim of this study is to test how much of the pattern of mean tropical precipitation and its response to climate change can be simulated from $T_{S}$ and $\mathrm{RH}_{S}$ patterns using a single-column model (SCM) under the WTG approximation. This study first investigates how much of the present-day annual-mean tropical rainfall pattern simulated by a general circulation model (GCM) can be reproduced by reconstructing only three elements: 1) the environment provided by the tropical mean-state, 2) the $T_{S}$ tropical pattern, and 3) the $\mathrm{RH}_{S}$ tropical pattern. Simulating a single atmospheric column, embedded in a predetermined environment, allows us to reconstruct those three elements since the only information needed is 1) the moisture and temperature profiles that describe the tropical environment, 2) the local $T_{S}$ "anomaly" at each location (departure from the environment), and 3) the local $\mathrm{RH}_{S}$ at each location. We use an SCM modified to implement the WTG approximation, so that precipitation in the column responds to the $T_{S}$ anomaly via the parameterization of the large-scale circulation. The latter is done using the so-called damped gravity wave (DGW) parameterization method (Bergman and Sardeshmukh 2004; Kuang 2008, 2011; Wang et al. 2013) and has been implemented following Daleu et al. (2015). Similar setups have been used in many studies (e.g., Sobel and Bretherton 2000; Chiang and Sobel 2002; Sobel et al. 2007; Sobel and Bellon 2009; Zhu and Sobel 2012). In addition, we implement the variation of moisture in the column in order to represent the precipitation response to $\mathrm{RH}_{S}$. The SCM is run multiple times to reconstruct the tropical $T_{S}$ and $\mathrm{RH}_{S}$ patterns from the corresponding parent GCM. The rainfall pattern reproduced from this reconstruction is then compared with the GCM. The experimental setup is described in detail in section 2.

In the second part of the study, increased atmospheric $\mathrm{CO}_{2}$ and uniform surface warming are independently applied to the SCM in order to investigate how much of the rainfall response can be reproduced by reconstructing 1) the change in the tropical mean-state environment, 2) the change in the $T_{S}$ tropical pattern, and 3) the change in the $\mathrm{RH}_{S}$ tropical pattern. Those three components are reconstructed for different aspects of $\mathrm{CO}_{2}$ forcing, such as uniform ocean warming, SST pattern change, or direct radiative effect of increased atmospheric $\mathrm{CO}_{2}$. They are taken from GCM atmosphere-only experiments in which these boundary conditions have been applied. Rainfall changes reproduced from these reconstructions in the SCM are then compared to the corresponding GCM experiment.

In addition to rainfall, we also investigate changes in convective mass fluxes, which can be used as a proxy for the intensity of the atmospheric circulation. Precipitation can be approximated as the product of near-surface specific humidity and vertically integrated convective mass flux. In a warmer and wetter climate, rainfall can increase even as convective mass flux decreases (Held and Soden 2006). Convective mass flux is expected to weaken in response to climate change, which has been attributed to the reduction of radiative cooling, or the enhanced warming of the subtropics, or the increase in dry static stability as a response to surface warming (e.g., Knutson and Manabe 1995; Held and Soden 2006; Vecchi and Soden 2007; Ma et al. 2012; Chadwick et al. 2013; Bony et al. 2013; He et al. 2014; He and Soden 2015). To test these mechanisms in the SCM, we use a more direct approach where we look at the direct response of the column to the forcing, without reconstructing $\mathrm{RH}_{S}$ patterns changes from the GCM. This way, we use the SCM to further understand whether the tropical circulation weakening is a direct or indirect, uniform or nonuniform response to increased atmospheric $\mathrm{CO}_{2}$. The weakening of the tropical circulation further affects the rainfall changes, which are also investigated.

\section{SCM description and setup}

The SCM uses the Met Office Unified Model Global Atmosphere version 7.1 in one dimension, which is also 
used in three dimensions in the atmosphere-only GCM HadGEM3 (Walters et al. 2019). The surface is prescribed, with no ocean or land surface model. The SCM has interactive radiation and solar diurnal cycle. There is no surface temperature variability applied on any time scale.

\section{a. Parameterization of the large-scale circulation in the SCM}

Conceptually, the SCM represents two atmospheric domains: the simulated column and a prescribed environment that typically represents the tropical mean. The environment is defined by reference vertical profiles of potential temperature $\theta$ and specific humidity $q$. To determine these profiles, the SCM is first run in radiative-convective equilibrium (RCE) mode: vertical velocity is set to zero so that convective heating balances radiative cooling. Surface temperature is prescribed and represents the tropical average SST. Reference profiles of $\theta$ and $q$ are determined from the equilibrated state of the RCE run. They will constitute the environment and initial state for DGW-parameterized SCM simulations, described below, with their mathematical framework detailed in appendix A.

In the single column simulated using the DGW parameterization, the prescribed surface temperature affects the column stability (compared to the initial state/ environment), which in turns affects convection and convective heating, warming or cooling the column. The column is also warmed or cooled by changes in the sensible heat flux and in water vapor and clouds, which then feed back on the column radiative heating. The vertical velocity $w^{\prime}$, which is the marker of the largescale circulation in the column, is parameterized to respond to the column temperature anomaly. The subsequent vertical advection of $\theta$ relaxes the simulated $\theta$ profile toward the reference $\theta$ profile, maintaining approximate uniformity with the environment, as dictated by the WTG approximation (see schematic in Fig. 1). Together with the subsequent vertical advection of $q$, it further affects rainfall.

Another method commonly used is the WTG parameterization (Sobel and Bretherton 2000; Sobel et al. 2001), which is only used here in the online supplemental material. Note that both the DGW and the WTG parameterization methods follow the WTG approximation. The DGW parameterization of $w^{\prime}$, unlike the WTG parameterization, takes place in the whole column, including the boundary layer, without linear interpolation.

This SCM setup represents the local effect of $T_{S}$ patterns on convective instability and thus free-tropospheric latent heating, which then drives low-level convergence (represented by the vertical velocity in the SCM) and

\section{Simulated domain Environment}

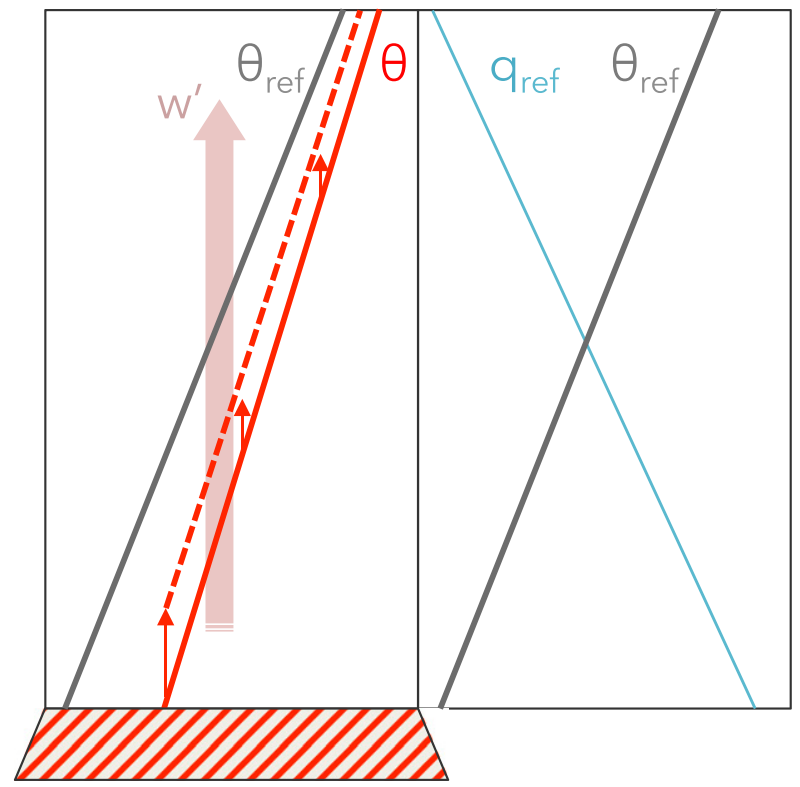

Fixed SST

FIG. 1. Schematic of the SCM with the DGW parameterization; $\theta_{\text {ref }}$ and $\theta$ are the reference and simulated potential temperatures, respectively, $q_{\text {ref }}$ is the reference specific humidity, and $w^{\prime}$ is the parameterized vertical velocity. The dashed red line represents the potential temperature profile once it has been relaxed toward the reference profile, via vertical advection (represented by the thin red arrows) by the parameterized vertical velocity.

convection. On the other hand, our SCM setup is not representative of the Lindzen and Nigam (1987) model, which describes the more direct effect of sharp $T_{S}$ gradients on low-level convergence via their influence on boundary layer pressure gradients. The SCM parameterization represents the effect of the $T_{S}$ anomaly regarding the tropical average, but is not able to simulate sharp $T_{S}$ gradients.

Horizontal advection of moisture between the environment and the simulated domain is modeled using simultaneously two different schemes that represent two different processes: 1) the horizontal advection by the locally parameterized mean divergent circulation ("lateral drawing") and 2) the horizontal advection by the mean rotational flow and transient eddies in the form of a relaxation of the domain $q$ profile toward the environmental $q$ profile ("moisture relaxation"). The time scale used for this relaxation is 1 day, which would be typical of horizontal moisture mixing between the simulated domain and a surrounding environment that is far enough away to be independent of the former. More details and mathematical formulation of the DGW parameterization and horizontal advection of moisture are given in appendix A. 


\section{b. Varying moisture in the SCM}

During a further stage of this study, in order to include variations of moisture and to be able to produce various values of $\mathrm{RH}_{S}$ (particularly low values found over land), we add to this setup a scaling of both surface evaporation (with a coefficient $\beta$ ) and environmental $q$ profile. The environmental $q$ profile is scaled with the same coefficient throughout the whole column. We use a range of combinations of those two scaling coefficients for each surface temperature. This allows us to vary moisture in the column, which also affects precipitation. It also allows us to have a better representation of the different tropical regions since there is no "weak moisture gradient" principle in the tropics. The $\beta$ and $q$ profile scaling coefficients are determined by spatial clustering analyses (see section 1 of the online supplemental material). Following these analyses, surface evaporation is varied using five coefficients that represent 1$)$ the ocean $(\beta=1), 2)$ rain forests $(\beta=$ $0.75), 3$ ) a $20 \%$ reduction of the evaporation over rain forests as is expected in response to $4 \times \mathrm{CO}_{2}$ increase (our vegetation-only forcing component with prescribed land gives a $17 \%$ reduction over rain forests latitudes over land) $(\beta=0.6), 4)$ wet regions $(\beta=0.5)$, and 5) semiarid regions $(\beta=0.2)$. The environmental $q$ profile is varied using seven coefficients that represent heavy rainfall convergence zones and rain forests (scaling coefficient $=1$ and 1.1 ), the northern and southern subtropics ( 0.8 and 0.7$)$, the northern and southern equatorial bands ( 1 and 0.9 ), deserts (0.4), and the Amazon during the wet season (1.25).

\section{c. Experimental design}

First, the SCM is run in RCE mode in order to determine the environment. Atmospheric $\mathrm{CO}_{2}$ concentrations are set to mid-1970s values. The run is performed for 100 days at $T_{s}^{\mathrm{RCE}}=300 \mathrm{~K}$, which is approximately the mean SST over the tropics $\left(20^{\circ} \mathrm{N}-20^{\circ} \mathrm{S}\right)$. Reference $\theta$ and $q$ profiles are determined from the time mean over the last 40 days of the RCE run. These profiles are then used as initial state and environment in the SCM runs under the DGW parameterization.

In the first stage of this study, the SCM is run 13 times under the DGW parameterization, with the surface temperature varying from 297.5 to $303.5 \mathrm{~K}$, in increments of $0.5 \mathrm{~K}$ ( $\beta$ and the environmental $q$ profile scaling coefficients are both set to 1$)$. This set of experiments will be referred to as SCM_CTRL_ $T_{S}$-only.

During a further stage of this study, the SCM is run multiple times with many possible combinations of $T_{S}$, $\beta$, and environmental $q$ profile scaling. In total a set of $455\left(13 T_{S} \times 5 \beta \times 7 q\right.$ scalings $) \mathrm{SCM}$ experiments are run to cover enough possibilities of $T_{S}, \mathrm{RH}_{S}$, and rainfall conditions in the column in order to reproduce rainfall patterns. We will refer to this set of experiments as SCM_CTRL.

In the last stage of this study, the set of 455 SCM experiments is replicated twice with two different perturbations. The control set of experiments mentioned above (SCM_CTRL) serves as the reference. A first set of perturbed experiments is performed with warmer mean conditions corresponding to a uniform warming of the surface by $4 \mathrm{~K}$ (SCM_4K). For this set of experiments, the $\mathrm{SCM}$ is first run in RCE mode at $T_{s+4 K}^{\mathrm{RCE}}=304 \mathrm{~K}$. Again, this run is performed for 100 days and the new reference $\theta$ and $q$ profiles are determined from the time mean over the last 40 days. These new profiles are then used as initial state and environment to perform a new set of runs under the DGW parameterization: the SCM is run again 455 times, varying $T_{S}$ from 301.5 to $307.5 \mathrm{~K}$ every $0.5 \mathrm{~K}$, and varying moisture using the same $\beta$ and $q$ profile scaling coefficients as in SCM_CTRL. A second set of perturbed experiments is performed with increased atmospheric $\mathrm{CO}_{2}$ corresponding to the $4 \times \mathrm{CO}_{2}$ forcing (SCM_4xCO2). For this set of experiments, the SCM is first run in RCE mode again at $T_{s}^{\mathrm{RCE}}=300 \mathrm{~K}$ as in SCM_CTRL, but with atmospheric $\mathrm{CO}_{2}$ multiplied by 4 . As before, the run is performed for 100 days, the new reference profiles are determined from the time mean over the last 40 days and then used as initial state and environment to perform a new set of runs under the DGW parameterization: the SCM is run again 455 times, varying $T_{S}, \beta$, and the $q$ profile scaling as in SCM_CTRL but with 4 times more $\mathrm{CO}_{2}$ in the atmospheric column.

\section{GCM experiments}

Different experiments from different GCMs are compared with the SCM results. They are all described in Table 1. The most relevant comparison is with the atmosphere-only experiment Atmospheric Modeling Intercomparison Project (AMIP) performed with the SCM's parent GCM HadGEM3 (Walters et al. 2019). We consider 20 years of this experiment from 1989 to 2008 and refer to it as HG3-AMIP. In HG3-AMIP, prescribed SST is taken from observations.

To investigate the response to the $4 \times \mathrm{CO}_{2}$ forcing, we compare the preindustrial (piControl) and abrupt $4 \times$ $\mathrm{CO}_{2}$ simulations performed with the previous version of the Met Office Unified Model HadGEM2-ES (Martin et al. 2011). To decompose the $4 \times \mathrm{CO}_{2}$ forcing, we use atmosphere-only experiments, each perturbed with one isolated component of the forcing (Table 1). Some of them have been performed with HadGEM2-ES and are described in more detail in Chadwick et al. (2017) (piSST, p4KSST, a4SST). At the time of writing, none of these experiments have been performed with HadGEM3 (the 
TABLE 1. GCM experiments used in this study (either directly analyzed or used for their output to perform other experiments). For each experiment: name (in this paper), GCM used to perform it, atmospheric $\mathrm{CO}_{2}$ forcing, interacting plant physiology, SST forcing, and land $T_{S}$ forcing.

\begin{tabular}{|c|c|c|c|c|c|}
\hline Name & GCM & $\mathrm{CO}_{2}$ & Plant physiology & SST & Land conditions \\
\hline HG3-AMIP & HadGEM3 & Observations 1989-2008 & On & Observations 1989-2008 & Free \\
\hline piControl & HadGEM2-ES & Preindustrial & On & Free & Free \\
\hline abrupt $4 \times \mathrm{CO}_{2}$ & HadGEM2-ES & Preindustrial $\times 4$ & On & Free & Free \\
\hline piSST & HadGEM2-ES & Observations 1979-2008 & On & piControl & Free \\
\hline p4KSST & HadGEM2-ES & piSST & On & $\begin{array}{l}\text { Uniform } 4 \mathrm{~K} \text { warming from } \\
\text { piControl }\end{array}$ & Free \\
\hline a4SST & HadGEM2-ES & piSST & On & abrupt $4 \times \mathrm{CO}_{2}$ & Free \\
\hline AMIP & ACCESS1.0 & Observations 1979-2008 & On & Observations 1979-2008 & Free \\
\hline AMIP_4xCO2tot & ACCESS1.0 & AMIP $\times 4$ & On & AMIP & Free \\
\hline AMIP_4xCO2rad & ACCESS1.0 & AMIP $\times 4$ & Off & AMIP & Free \\
\hline AMIP_PL & ACCESS1.0 & AMIP & On & AMIP & AMIP \\
\hline AMIP_PL_4xCO2tot & ACCESS1.0 & AMIP & On & AMIP & AMIP_4xCO2tot \\
\hline AMIP_PL_4xCO2rad & ACCESS1.0 & AMIP & Off & AMIP & AMIP_4xCO2rad \\
\hline AMIP_4xCO2tot_PL & ACCESS1.0 & AMIP $\times 4$ & On & AMIP & AMIP \\
\hline AMIP_4xCO2rad_PL & ACCESS1.0 & AMIP $\times 4$ & Off & AMIP & AMIP \\
\hline
\end{tabular}

SCM's parent GCM); HadGEM2-ES was then most likely the closest model to be compared to the SCM. The other atmosphere-only experiments used in this study have prescribed land in addition to prescribed ocean. They have only been performed with ACCESS1.0 (Bi et al. 2013; Ackerley and Dommenget 2016) and are described in more detail in Ackerley et al. (2018). ACCESS1.0 and HadGEM2-ES are very similar models sharing the same configurations of their land surface and atmospheric components (including convection scheme). Using these "prescribed-land" experiments allows us to decompose the $4 \times \mathrm{CO}_{2}$ forcing more, since land surface changes are separated from ocean-surface changes.

For all these GCM experiments, the last 30 years are considered. The different components of the $4 \times \mathrm{CO}_{2}$ forcing built from combinations of these experiments are defined in Table 2 . The vegetation-only forcing with prescribed land shows the effect of the plant physiological response to $4 \times \mathrm{CO}_{2}$ with prescribed surface temperature over land and ocean. The $4 \times \mathrm{CO}_{2}$ radiative-only forcing with prescribed land shows the $4 \times \mathrm{CO}_{2}$ radiative-only effect (no plant physiology change) with prescribed surface temperature over land and ocean. Other definitions given in Table 2 are self-explanatory.

\section{Present-day climate}

\section{a. Reproduction from surface temperature pattern only}

In this part we analyze SCM_CTRL_ $T_{S}$-only, where only the surface temperature varies (moisture can vary but evaporation and environmental $q$ profile scalings are set to 1$)$. This setup gives the expected rainfall response to the large-scale circulation induced by surface temperature patterns, under the WTG approximation.

SCM_CTRL_ $T_{S}$-only precipitation results are shown in Fig. 2a for each surface temperature, and compared with the HG3-AMIP distribution of precipitation over the ocean, for each corresponding SST bin. The qualitative relationship between SST and precipitation is fairly well reproduced in the SCM, but the SCM precipitation is too sensitive to the surface temperature compared with the GCM. This is associated with an overestimation of the sensitivity of the parameterized vertical velocity $w^{\prime}$ to the surface temperature (Fig. 2b).

There are many possible reasons for the SCM not to perfectly reproduce the GCM rainfall. Our SCM setup is an idealized model, based on an approximation and with simplified representation of moisture advection. Besides,

TABLE 2. Definition of the different components of the $4 \times \mathrm{CO}_{2}$ forcing from the experiments listed in Table 1 .

\begin{tabular}{ll}
\hline \multicolumn{1}{c}{ Component } & \multicolumn{1}{c}{ Definition } \\
\hline Uniform + 4-K ocean warming & p4KSST-piSST \\
SST pattern-only & a4SST-p4KSST \\
Land warming induced by $4 \times \mathrm{CO}_{2}$ radiative-only forcing & AMIP_PL_4xCO2rad-AMIP_PL \\
Vegetation-only forcing with prescribed land & AMIP_4xCO2tot_PL-AMIP_4xCO2rad_PL \\
Land warming induced by vegetation-only forcing & AMIP_PL_4xCO2tot-AMIP_PL_4xCO2rad \\
$4 \times \mathrm{CO}_{2}$ radiative-only forcing with prescribed land & AMIP_4xCO2rad_PL-AMIP_PL \\
\hline
\end{tabular}


the WTG approximation is not always accurate, as the free tropospheric temperature is not perfectly uniform across the tropics, particularly outside the equatorial band $\left(10^{\circ} \mathrm{N}-\right.$ $10^{\circ} \mathrm{S}$ ) and over land regions outside the equatorial band (Todd et al. 2018). On the other hand, its accuracy over land regions within the equatorial band has been shown for the Amazon (Anber et al. 2015). Our SCM setup is also not meant to capture all the mechanisms that exist in the GCM, but rather only the effect of $T_{S}$ patterns on the large-scale circulation via convective instability and free-tropospheric heating patterns. However, the most likely reason for the oversensitivity of $w^{\prime}$ and precipitation to the surface temperature is the relative isolation and lack of variability of the simulated single column. In the GCM, each column is affected by transients, weather systems, and disturbances from nearby columns that are lacking in the SCM. As it is not disturbed, the vertical velocity in the single column is relatively free to grow or decline, as a consequence of positive feedbacks detailed in section S2 of the supplemental material. As a result, the single column reaches a steady state after a few days that tends to be either too wet or too dry, even though horizontal mixing of moisture prevents it from getting excessive (see section $\mathrm{S} 2$ ).

Figure 3b shows SCM_CTRL_ $T_{S}$-only precipitation results on a map, projecting it on HG3-AMIP surface temperatures (see appendix B). Over the ocean, the precipitation pattern is sensible (correlation over the ocean: 0.7 ; correlation including land: 0.42 ). Not surprisingly, it closely follows the SST pattern (not shown), raining over warm regions. As found in other studies, tropical annual mean rainfall can be fairly sensibly reproduced by an SCM under the WTG approximation (Sobel and Bretherton 2000; Zhu and Sobel 2012). Over land, precipitation is generally underestimated, as a result of land regions being relatively cold compared to the tropical average; except over the Sahel, northern Australia, and India, which are the hottest regions of the tropics and where precipitation is overestimated.

As mentioned before, this SCM setup represents the effect of $T_{S}$ patterns on the large-scale circulation via convective instability and free-tropospheric heating patterns. While this drives most of the low-level wind convergence in the tropics, other mechanisms have been suggested to dominate in some particular regions, such as regions of strong meridional SST gradients near the equator, and on the flanks of the oceanic intertropical convergence zone (ITCZ) (Chiang et al. 2001; Diakhaté et al. 2018). In particular, in the central-eastern Pacific, boundary layer pressure gradients driven by the strong meridional SST gradients create low-level wind convergence that forces convection, rather than being a

\section{a) Precipitation against SST}

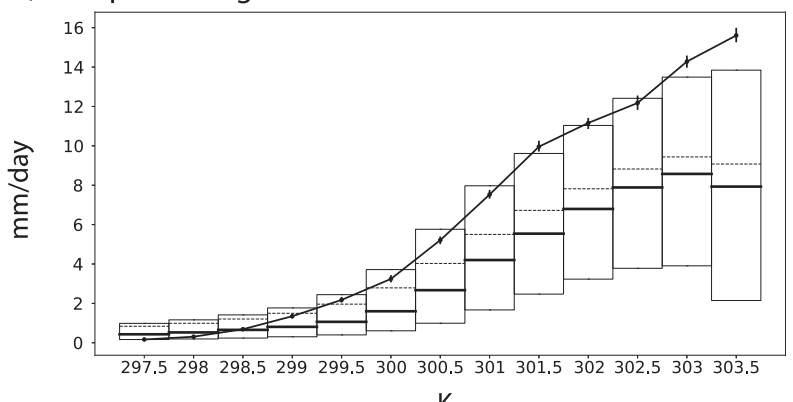

b) Vertical velocity at $500 \mathrm{hPa}$ against SST

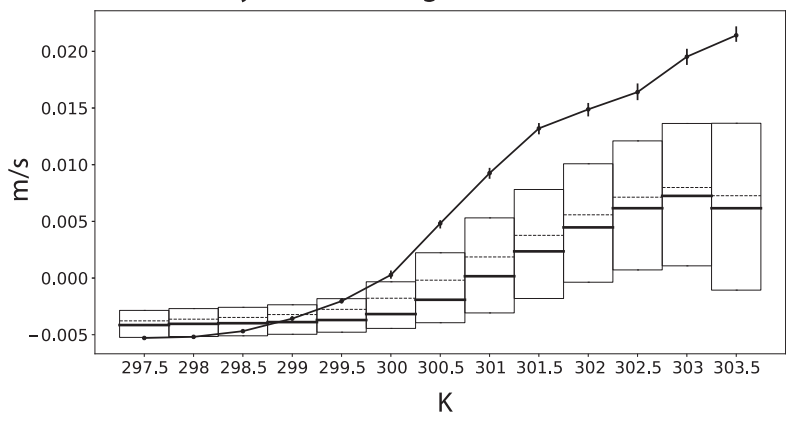

FIG. 2. (top) Relationship between precipitation and SST in the SCM_CTRL_ $T_{S}$-only runs (black line) and in the GCM HG3-AMIP (boxes encompass $50 \%$ of the values between the 25th and the 75th percentiles, the median is plain bold, and the mean is dashed). Each SCM experiment corresponds to one prescribed surface temperature value and one resulting equilibrated mean precipitation (taken as the time mean over the last 40 days of the 100-day-long run to keep only the equilibrated period). Error bars are drawn between the 25th and the 75th percentiles of the range of precipitation values occurring during the equilibrated period of the run. In HG3-AMIP, boxes show the distribution of precipitation found for each SST bin, considering all months and all oceanic grid points of the tropics $\left(20^{\circ} \mathrm{N}-20^{\circ} \mathrm{S}\right)$. Boxes are $0.5 \mathrm{~K}$ wide and correspond to the surface temperature values used in the SCM experiments. (bottom) As in the top panel, but for the relationship between vertical velocity at $500 \mathrm{hPa}$ and SST.

consequence of it (Lindzen and Nigam 1987; Back and Bretherton 2009). Our SCM setup does not capture this influence of $T_{S}$ gradients on the large-scale circulation via boundary layer pressure gradients. This could explain some of the differences between the GCM and the SCM, such as the too-weak and too-wide ITCZ produced by SCM_CTRL_ $T_{S}$-only in the northeast Pacific (Fig. 3b), and thus support the idea that the effect of $T_{S}$ gradients plays a key role in this region.

Figure 4 a confirms the good correspondence between the SCM and the GCM precipitation over the ocean, as shown by the linear regression of one on another, although the SCM tends to generally overestimate rainfall. In particular, over some oceanic grid points (blue dots), the annual-mean precipitation is high in the SCM 
a) HG3-AMIP: annual-mean precipitation

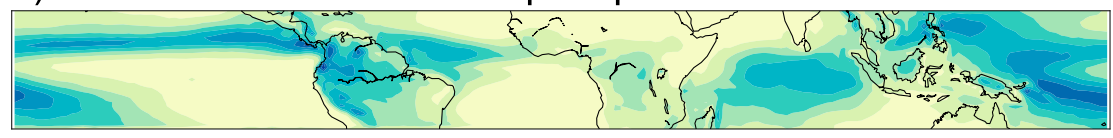

b) SCM varying Ts only: annual-mean precipitation projection

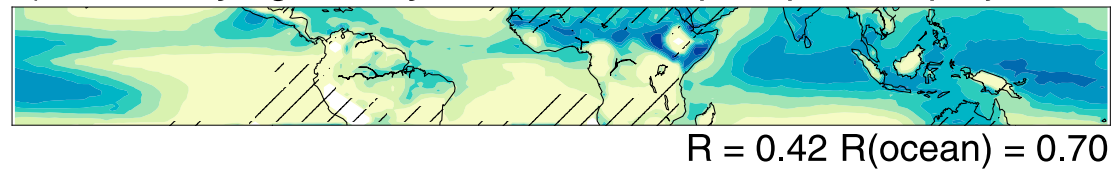

c) SCM varying Ts and moisture: annual-mean precipitation projection

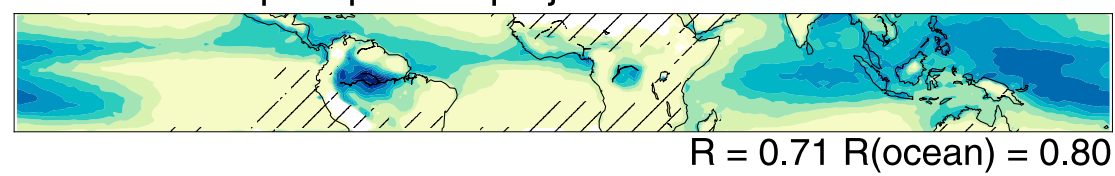

d) $\mathrm{c}-\mathrm{a}$

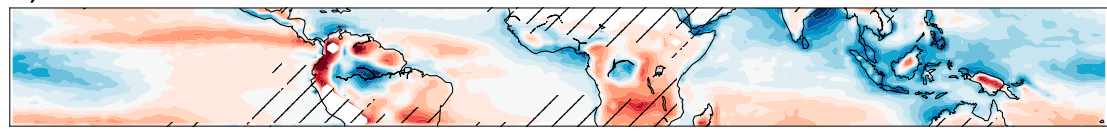

$\mathrm{mm} / \mathrm{day}$

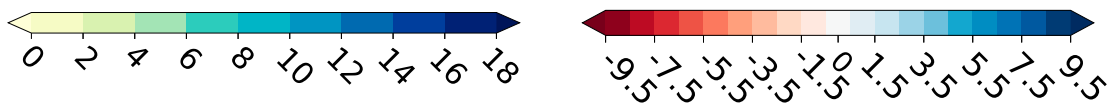

FIG. 3. Annual-mean precipitation in HG3-AMIP and from SCM runs. (a) HG3-AMIP annual mean precipitation. (b) Projection of SCM_CTRL_T $T_{S}$-only precipitation results on HG3-AMIP $T_{S}$ (see appendix B). (c) Projection of SCM_CTRL precipitation results on HG3-AMIP $T_{S}$ and $\mathrm{RH}_{S}$ (see appendix B). (d) Difference between (c) and (a). Hatched regions are where there are less than 10 months of the climatological year for which SCM runs correspond to the region and can be projected on it. Note that $R$ on the bottom right is the Pearson pattern correlation with (a); $R$ (ocean) is computed over the ocean only.

but low in the GCM, which corresponds to SCM overestimations at high SSTs on Fig. 2a. Figure 4a also confirms the lack of correspondence over land, with the SCM raining too much in GCM dry regions, and not enough in GCM rainy regions (given the poor correlation over land, no linear regression is shown).

In the real world, precipitation and SST patterns do not exactly match. One thing in particular that SCM CTRL_ $T_{S}$-only is missing is the spatial variation of nearsurface and atmospheric moisture. Only one moisture profile was used to define the environment in SCM CTRL_ $T_{S}$-only, while moisture is not uniform across the tropics. Variations of moisture are especially an issue for representing relatively cold but wet land regions such as rain forests, or hot but dry land regions such as deserts. In the next section and the rest of this study, the column moisture will be varied (in addition to surface temperature), using SCM_CTRL, to address these issues.

\section{b. Reproduction from surface temperature and relative humidity patterns}

From now on we analyze the SCM_CTRL set of experiments (see section 2c), where not only the surface temperature varies but also moisture, through variations of evaporation and environmental $q$ profile scalings. Figure 3c shows SCM_CTRL precipitation results on a map, projecting it on HG3-AMIP $T_{S}$ and $\mathrm{RH}_{S}$ (see appendix $\mathrm{B}$ ). Considering moisture variation clearly improves the projected rainfall pattern (higher correlation with HG3-AMIP: 0.8 over the ocean and 0.71 including land). Over land, varying moisture now allows the representation of relatively cold and wet regions like rain forests and hot, dry regions like deserts. In the GCM, $\mathrm{RH}_{S}$ affects precipitation, but precipitation also feeds back on $\mathrm{RH}_{S}$, so the causality between moisture and rainfall patterns is unclear. In the SCM, the causality 
a) SCM varying Ts only

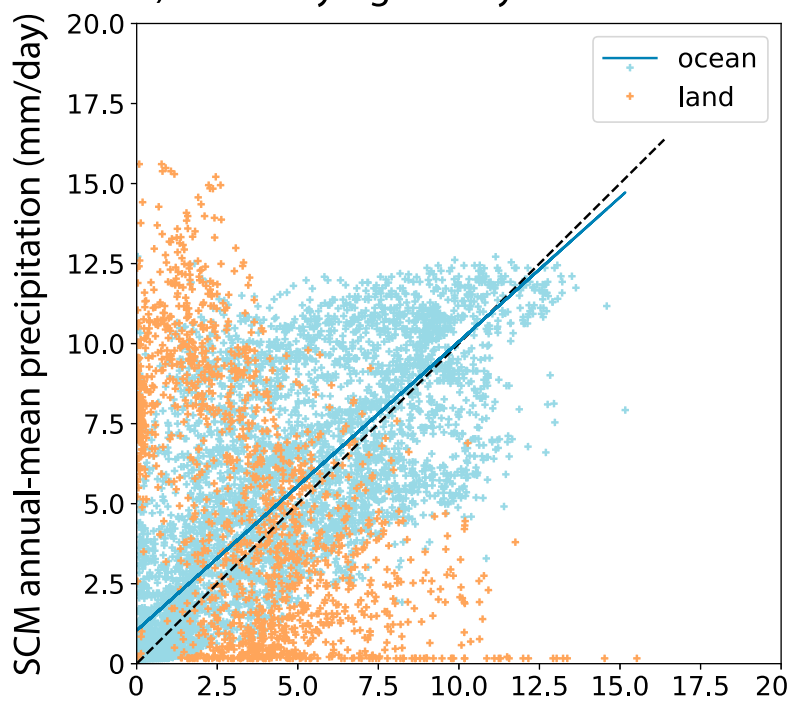

b) SCM varying Ts and moisture

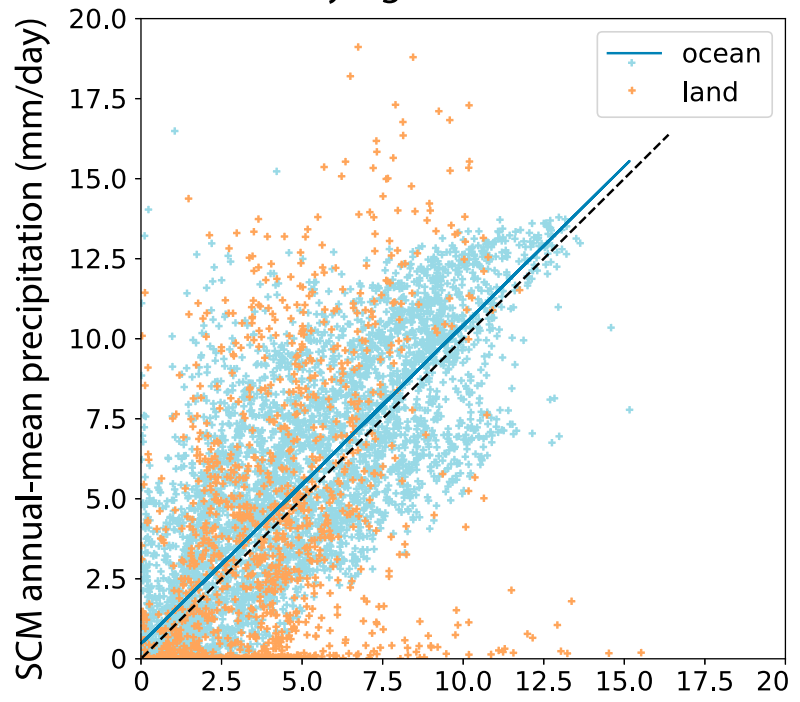

GCM annual-mean precipitation ( $\mathrm{mm} /$ day)

FIG. 4. SCM against GCM (HG3-AMIP) annual-mean precipitation. (a) SCM_CTRL_ $T_{S}$-only against HG3-AMIP (i.e., precipitation from Fig. 3b plotted against precipitation from Fig. 3a, taken over the whole tropics). (b) SCM_CTRL against HG3-AMIP (i.e., precipitation from Fig. 3c plotted against precipitation from Fig. 3a). Orange dots are land grid points and blue dots are ocean grid points. Corresponding linear regressions are shown for ocean (blue). The dashed black line shows the $y=x$ one-to-one line.

is clearer, even though $\mathrm{RH}_{S}$ variations are not directly prescribed (but induced by variations in the moisture coefficients), because precipitation has very limited ways of feeding back on to $\mathrm{RH}_{S}$.

But what is the SCM not able to capture? Figure 3d highlights differences with the HG3-AMIP precipitation pattern. The sensitivity of precipitation to the surface temperature remains overestimated in the SCM. This is consistent with rainfall over the ocean being too extended spatially and generally too strong, while regions with low rain rates are generally too dry. This is also consistent with land regions remaining too dry, except for some rain forests. It remains unclear whether it is due to the SCM parameterization or whether it has a physical explanation such as rainfall being driven by other factors than local surface temperature and humidity. Over land, low thermal inertia, consequently strong diurnal cycle, and orography or soil moisture play a large role in circulation and convective systems, none of which are directly represented in the SCM. For example, the mean precipitation over land partly results from the diurnal cycle of surface temperature, which may be very different from the precipitation resulting from the mean surface temperature. Another thing the SCM does not reproduce is the fact that convection over coastal land drives low-level mass divergence over nearby coastal ocean, forcing subsidence and advective drying there, which are not well captured by $T_{S}$ and moisture patterns. Over the Maritime Continent, for example, even though considering moisture heterogeneity and transport allows a better representation of rainfall, the SCM still overestimates oceanic rainfall near the coasts. It is generally the case for African and Asian tropical coasts as well.

Figure $4 \mathrm{~b}$ confirms that the correspondence between the SCM and the GCM precipitation, over both ocean and land, is substantially improved by considering moisture variations. Despite this strong improvement, the SCM still tends to be either too wet or too dry over land, exhibiting two populations of grid points in GCM rainy regions: one where the SCM remains dry and another one where the SCM overestimates rainfall. Given the existence of these two populations, regressing the SCM rainfall linearly on the GCM rainfall over land would not be sensible. Overall, the SCM still overestimates rainfall over both land and ocean, as further confirmed by the $20^{\circ} \mathrm{N}-20^{\circ} \mathrm{S}$ tropically averaged annual-mean rainfall, which is $4.84 \mathrm{~mm} \mathrm{day}^{-1}$ in the SCM against $4.34 \mathrm{~mm} \mathrm{day}^{-1}$ in the GCM.

\section{Perturbed climate experiments}

In the GCM, we choose to decompose the $4 \times \mathrm{CO}_{2}$ forcing into 1) land warming due to the plant physiological response to $4 \times \mathrm{CO}_{2}, 2$ ) land warming due to the $4 \times \mathrm{CO}_{2}$ radiative-only effect, 3 ) effects of the plant physiological response to $4 \times \mathrm{CO}_{2}$ with prescribed $T_{S}$ over land and ocean, 4) change in the SST pattern, 5) the $4 \times \mathrm{CO}_{2}$ radiative-only effect (no plant physiology) with prescribed 


\section{a) Fully coupled $4 \times \mathrm{CO}_{2}$}

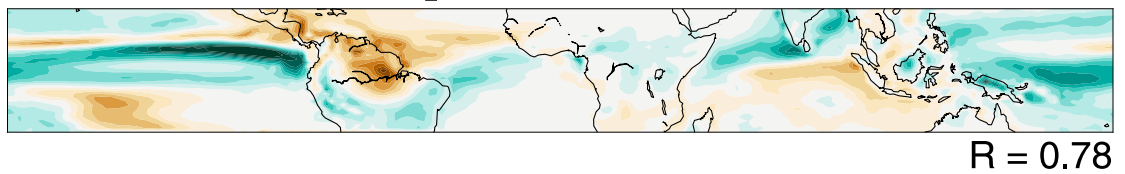

b) Recomposed response to atmosphere-only forcings

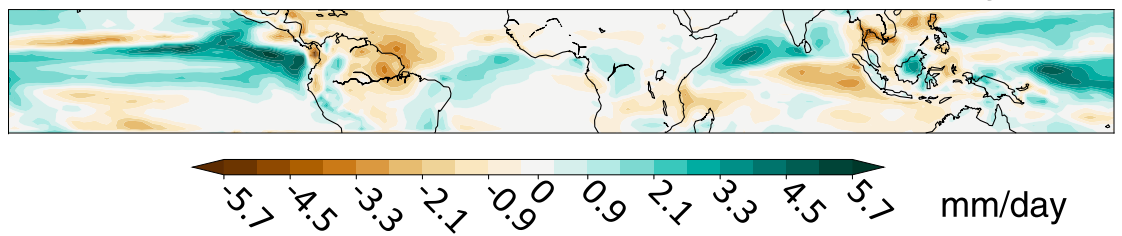

FIG. 5. Annual-mean precipitation responses to a combination of forcings in the GCM. (a) Fully coupled response to increased atmospheric $\mathrm{CO}_{2}$ : abrupt $4 \times \mathrm{CO}_{2}$-piControl. (b) Sum of the responses to six different components of the $4 \times \mathrm{CO}_{2}$ forcing, namely 1 ) the change in the SST pattern, 2) the land warming due to the $4 \times \mathrm{CO}_{2}$ radiative-only effect, 3) the effect of the plant physiological response to $4 \times \mathrm{CO}_{2}$ with prescribed $T_{S}$ over land and ocean, 4) the land warming due to the plant physiological response to $\left.4 \times \mathrm{CO}_{2}, 5\right)$ the $4 \times \mathrm{CO}_{2}$ radiativeonly effect (no plant physiology) with prescribed $T_{S}$ over land and ocean, and 6) the uniform $+4 \mathrm{~K}$ ocean warming: a4SST-piSST + AMIP_4xCO2tot_PL + AMIP_PL_4xCO2tot2xAMIP_PL. The term $R$ is the Pearson pattern correlation between (a) and (b).

$T_{S}$ over land and ocean, and 6) uniform $+4-\mathrm{K}$ ocean warming. The first three correspond to perturbations in the land surface. The last two correspond to uniform perturbations that strongly affect the atmospheric budget. We use GCM experiments described in section 3 that isolate those different components of the $4 \times \mathrm{CO}_{2}$ forcing. Figure $5 \mathrm{a}$ shows the full annual-mean precipitation response to the $4 \times \mathrm{CO}_{2}$ forcing, as given by abrupt $4 \times \mathrm{CO}_{2}$, and Fig. 5b shows the sum of the six components described above. In Figs. $5 \mathrm{a}$ and $5 \mathrm{~b}$ the patterns and magnitudes are consistent (correlation: 0.78), suggesting that those six components add up nearly linearly and that looking at each one separately can help us to understand the full response.

To reproduce each forcing component with the SCM, we use the two sets of SCM experiments perturbed with surface warming (SCM_4K) and $4 \times \mathrm{CO}_{2}$ (SCM_4xCO2) described in section 2c. Note that in these cases, the SCM results are compared with experiments performed with HadGEM2-ES and ACCESS1.0, which use different physical schemes than HadGEM3 (the SCM's parent GCM). At the time of this study, these experiments have not been performed with HadGEM3. Therefore, it is worth keeping in mind that this could cause differences between the GCM experiments and the SCM results. However, we believe this is unlikely to cause major differences, because SCM CTRL projects very well on both piSST (HadGEM2ES), with a pattern correlation of 0.68 , and AMIP_PL (ACCESS1.0), with a pattern correlation of 0.73 (when applying the same method as in section $4 \mathrm{~b}$ and Fig. 3c; not shown).

\section{a. Perturbed land surface}

Figure 6 shows annual-mean precipitation changes associated with different forcing components, as simulated by the GCM (top of each panel) and reproduced by the SCM (bottom of each panel). Plant transpiration weakens in response to increased atmospheric $\mathrm{CO}_{2}$, reducing evapotranspiration and warming the land surface by reducing its cooling capacity (Sellers et al. 1996; Cox et al. 1999; Dong et al. 2009). Land warming induced by this vegetation forcing, when isolated, results in a general rainfall increase over land (Fig. 6a). When land warming is induced by the direct radiative effect of increased atmospheric $\mathrm{CO}_{2}$, the response is similar (Fig. 6c) although with a smaller magnitude, as the magnitude of land warming is also smaller (land warms by $0.74^{\circ} \mathrm{C}$ on average when induced by vegetation and by $0.38^{\circ} \mathrm{C}$ when induced by the radiative $\mathrm{CO}_{2}$ effect). In both cases, the SCM captures the general rainfall increase over land (Figs. 6b,d), confirming that land warming brings more rainfall over land.

In the case of the vegetation-induced land warming, the SCM reproduces the right magnitudes of rainfall increases (Fig. 6b), despite the strong sensitivity of its precipitation to surface temperatures (shown in the previous section). This is because we take into account $\mathrm{RH}_{S}$ variations, which we reconstruct in the SCM through variations of evaporation and environmental moisture profile (affecting horizontal moisture advection). Land warming is generally associated with reduced $\mathrm{RH}_{S}$ over land (Joshi et al. 2008; O'Gorman and 

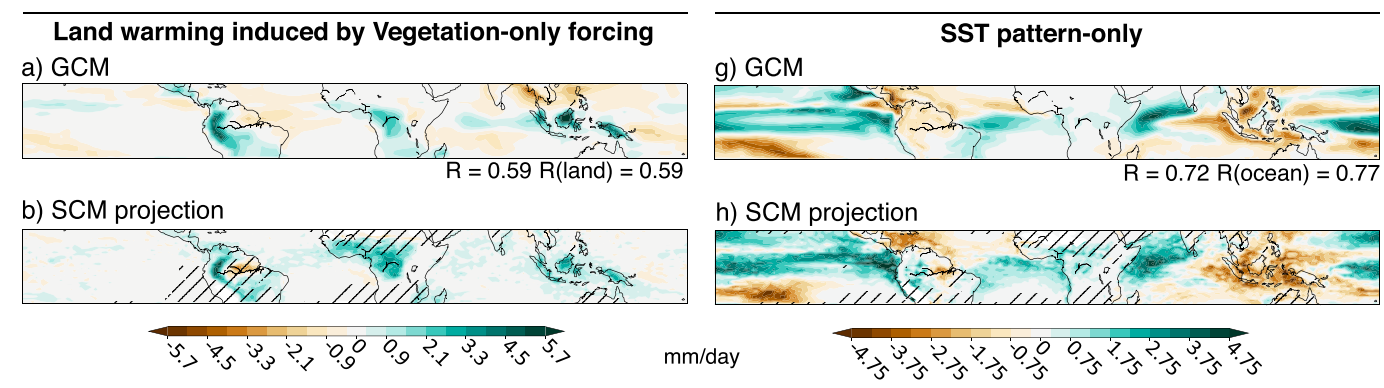

\section{h) SCM projection}

Land warming induced by $4 \times \mathrm{CO} 2$ radiative-only forcing c) GCM
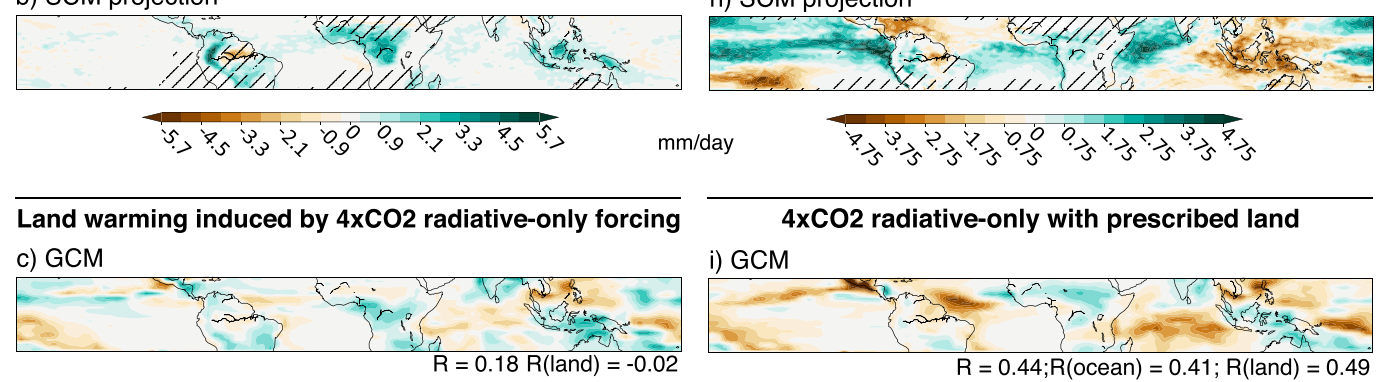

.
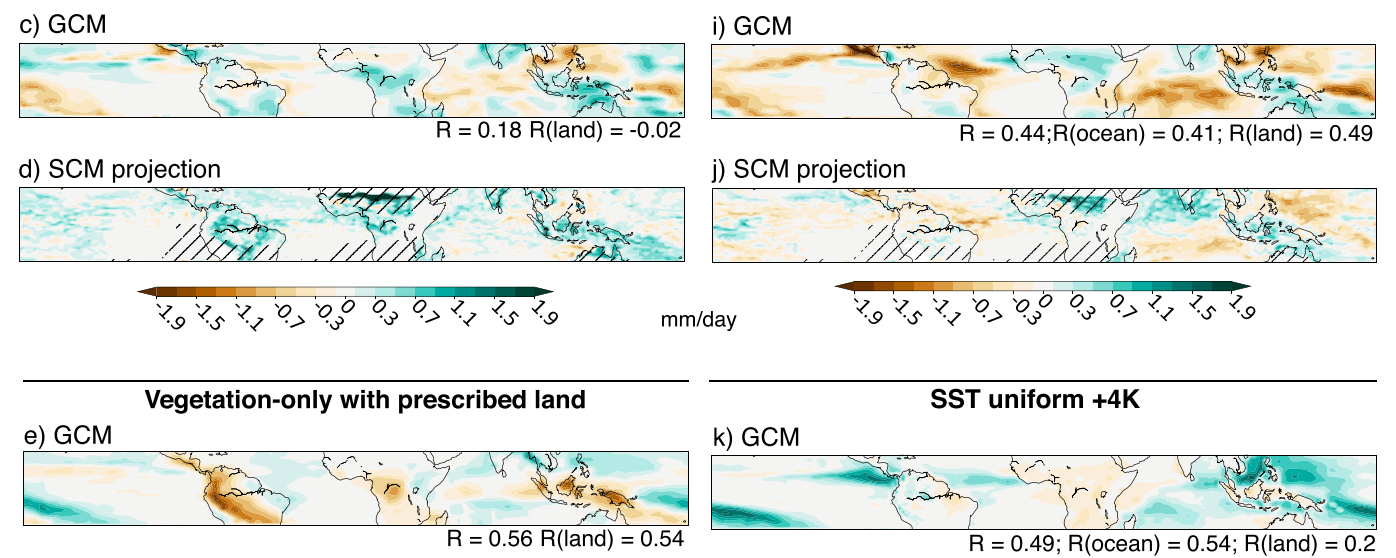

f) SCM projection allowing only changes in evaporation
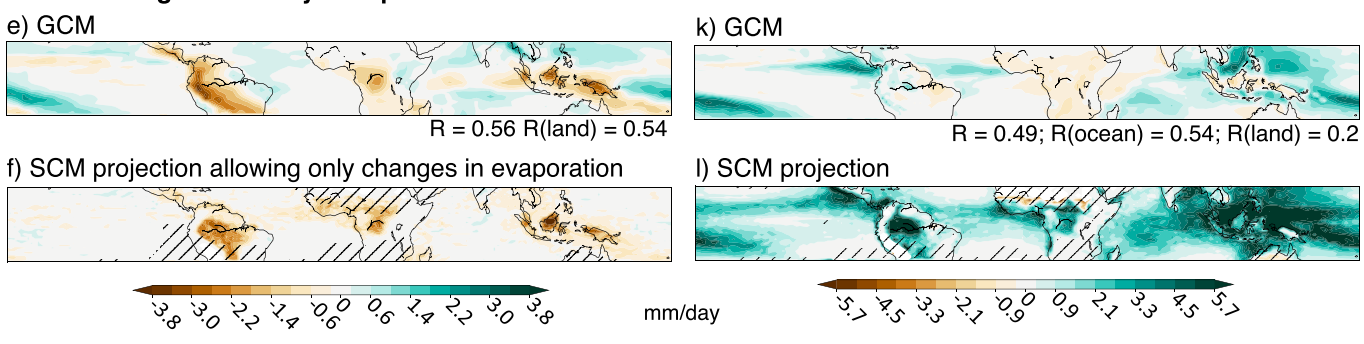

FIG. 6. Annual-mean precipitation responses to different components of the $4 \times \mathrm{CO}_{2}$ forcing, in the GCM and from SCM runs. Each panel shows on the top the GCM rainfall response and on the bottom the corresponding SCM projection. When not specified otherwise, projections are done using $T_{S}$ and $\mathrm{RH}_{S}$ (see appendix B). Hatched regions are where there are less than 10 months of the climatological year for which SCM runs correspond to the region and can be projected on it (for either one of the two projections compared). The term $R$ is the Pearson pattern correlation between the SCM projection and the GCM; $R$ (ocean) is when considering the ocean only and $R$ (land) when considering land only. (a) AMIP_PL_4xCO2tot-AMIP_PL_4xCO2rad. (b) [Projection (proj.) of SCM_CTRL on AMIP_PL_4xCO2tot]-[proj. of SCM_CTRL on AMIP_PL_4xCO2rad]. (c) AMIP_PL_4xCO2rad-AMIP_PL. (d) [Proj. of SCM_CTRL on AMIP_PL_4xCO2rad]-[proj. of SCM_CTRL on AMIP_PL]. (e) AMIP_4xCO2tot_PLAMIP_4xCO2rad_PL. (f) [Proj. of SCM_4xCO2 on AMIP_4xCO2tot_PL, done using $T_{S}$ and $\mathrm{RH}_{S}$ and using the same $q$ profile scaling as for the proj. of SCM_4xCO2 on AMIP_4xCO2rad_PL (so that only evaporation is allowed to change; see appendix B)]-[proj. of SCM_4xCO2 on AMIP_4xCO2rad_PL]. (g) a4SST-p4KSST. (h) [Proj. of SCM_ $4 \mathrm{~K}$ on a4SST]-[proj. of SCM_4K on p4KSST]. (i) AMIP_4xCO2rad_PL-AMIP_PL. (j) [Proj. of SCM_4xCO2 on AMIP_4xCO2rad_PL]-[proj. of SCM_CTRL on AMIP_PL]. (k) p4KSST-piSST. (1) [Proj. of SCM_4K on p4KSST][proj. of SCM_CTRL on piSST].

Muller 2010; Simmons et al. 2010; Chadwick et al. 2016; Byrne and O'Gorman 2016), as confirmed by Fig. S8g in the supplemental material, making the SCM able to capture land rainfall increases with the right magnitudes. Land warming induced by vegetation also creates a drying patch over the eastern Amazon (Fig. 6a), which is captured by the SCM (Fig. 6b) thanks to the associated $\mathrm{RH}_{S}$ reduction (Fig. $\mathrm{S} 8 \mathrm{~g}$ ). The causality between reduced rainfall and reduced $\mathrm{RH}_{S}$ remains unclear. There are a few other spots of land rainfall decrease (northeastern
Brazil, central-eastern Africa, continental southeastern Asia) that the SCM fails to capture. As a result, it overestimates the average land rainfall increase (Fig. S9a).

In the case of the $\mathrm{CO}_{2}$-induced land warming, the SCM overestimates the land rainfall increase on average (Fig. S9b). Both $T_{S}$ and $\mathrm{RH}_{S}$ changes are of weak magnitudes, making it difficult to evaluate the sensitivity of the SCM to these changes. The resulting correlation coefficient between the patterns of Figs. $6 \mathrm{c}$ and $6 \mathrm{~d}$ is very weak. Note that the strong rainfall increase over the 
Sahara is not significant, because there are less than 6 months of the climatological year for which SCM runs correspond to this region and can be projected on it (not shown).

As mentioned above, the vegetation response to increased $\mathrm{CO}_{2}$ reduces evapotranspiration and subsequently warms the surface over land. The effect of land surface warming, detailed above, can now be switched off by fixing the land surface temperature. This allows us to isolate the effect of reduced evapotranspiration, which is to generally reduce rainfall over land (Fig. 6e). Both the pattern and magnitudes of land rainfall decreases are well captured by the SCM (Fig. 6f; see also Fig. S9c). This shows that the sensitivity of the SCM precipitation to $\mathrm{RH}_{S}$ is sensible. Note that for this particular projection, we only use variations in evaporation (using $\beta$ ) to reconstruct the $\mathrm{RH}_{S}$ pattern (i.e., we fixed horizontal advection of moisture), simply for more relevance and consistency with the GCM forcing. However, here again the SCM fails to capture a few spots of land rainfall increases (the same as in the land-warming case: northeastern Brazil, central-eastern Africa, continental southeastern Asia). As a result, the average land rainfall decrease is slightly overestimated by the SCM over tropical America and more strongly over Asia and Oceania.

Overall, when forcing is applied over land as is the case here, the SCM does not capture rainfall changes over the ocean, or over some land regions like northeastern Brazil, central-eastern Africa, and continental southeastern Asia. This highlights the role of large-scale circulation changes that are independent from local surface changes and cannot be represented by the SCM. Over the eastern Amazon in particular, the crucial role of remotely driven changes in low-level wind convergence, independent from local surface changes, has been shown by Saint-Lu et al. (2019). The SCM results are consistent with this idea that changes in the local surface temperature and evaporation do not dominate regional rainfall changes over land everywhere.

\section{b. Perturbed sea surface temperature pattern}

Several studies have shown that changes in SST patterns drive most of the changes in rainfall patterns over the tropical oceans (Xie et al. 2010; Ma and Xie 2013; Chadwick et al. 2014; Kent et al. 2015). The pattern of the rainfall response to changes in the SST pattern is well captured by the SCM (correlation: 0.72), especially over the ocean (correlation: 0.77 ), as shown by Figs. $6 \mathrm{~g}$ and $6 \mathrm{~h}$. Despite the strong sensitivity of the SCM precipitation to the SST, the magnitude of the rainfall response is also well captured, thanks to the reconstruction of the $\mathrm{RH}_{S}$ pattern via variations of moisture (not shown). When regressing linearly the SCM precipitation change on the
GCM precipitation change over the ocean (Fig. S10), the slope is very close to 1 with an origin very close to 0 , confirming the good correspondence in the magnitudes of rainfall changes between the SCM and the GCM.

Overall, this result confirms the dominance of the warmer-get-wetter mechanism in the rainfall response to SST pattern changes over the tropical ocean in GCMs. In particular, the local effect of SST pattern change on convective instability appears to dominate over the influence of SST gradients on boundary layer pressure gradients [the Lindzen and Nigam (1987) model], as this second effect is not well represented by the SCM.

Over land, the rainfall response to SST pattern changes is not well captured by the SCM. This is not surprising, since the GCM land rainfall responds to the change in the SST pattern via the atmosphere, with a top-down forcing-which we attempt to capture in the SCM with a bottom-up forcing (using the surface temperature and relative humidity). Recall that here, unlike for land surface perturbations, only the ocean surface is prescribed in the GCM. Changes in the SST pattern directly drive circulation changes over land, which are thus not driven by the land surface. In this case, the only way the SCM can capture the GCM land rainfall changes is via their signatures on the land surface; for example some drying over the Amazon is captured, probably because of the subsequent $\mathrm{RH}_{S}$ reduction.

\section{c. Perturbed atmospheric $\mathrm{CO}_{2}$}

\section{1) Circulation Weakening}

As shown in previous studies, the atmospheric overturning circulation weakens as a direct response to increased atmospheric $\mathrm{CO}_{2}$ (Bony et al. 2013; He and Soden 2015; Chadwick et al. 2014). Additional evidence for this is provided by the reduction of the vertically integrated convective mass flux $M_{\mathrm{INT}}$ (positive upward) simulated by the GCM in response to the $4 \times \mathrm{CO}_{2}$ radiative-only forcing, especially over the ocean (Fig. 7a). Two important hypotheses to explain the $\mathrm{CO}_{2}$-induced circulation weakening are that 1 ) reduced radiative cooling, directly due to increased atmospheric $\mathrm{CO}_{2}$, heats the atmosphere and suppresses convection, reducing the convective mass flux (i.e., reduced radiative cooling has to be balanced by reduced convective heating) (Bony et al. 2013); and 2) increasing $\mathrm{CO}_{2}$ warms dry regions (especially the subtropics) more than convective regions, reducing energy transports between ascent and descent regions and slowing down the associated circulation. Merlis (2015) suggested that the troposphere warms more in dry regions than in wet regions because increasing $\mathrm{CO}_{2}$ reduces radiative cooling more efficiently as there is less absorption overlap with water vapor and clouds. Both hypotheses could be captured 
a)

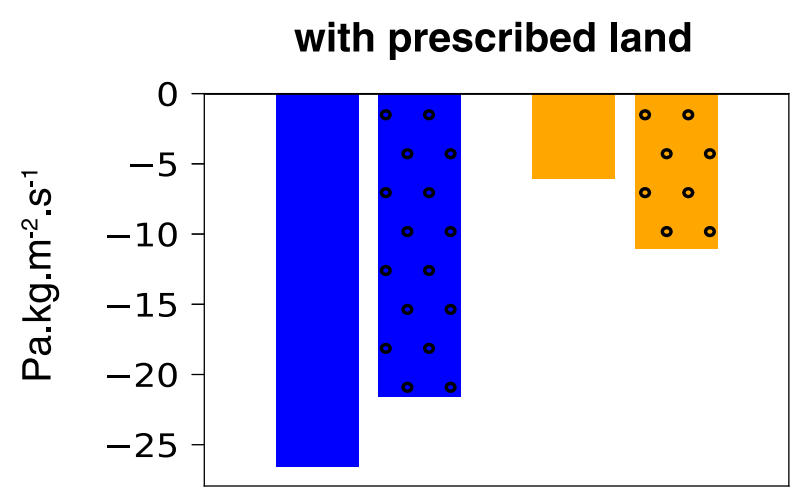

b)

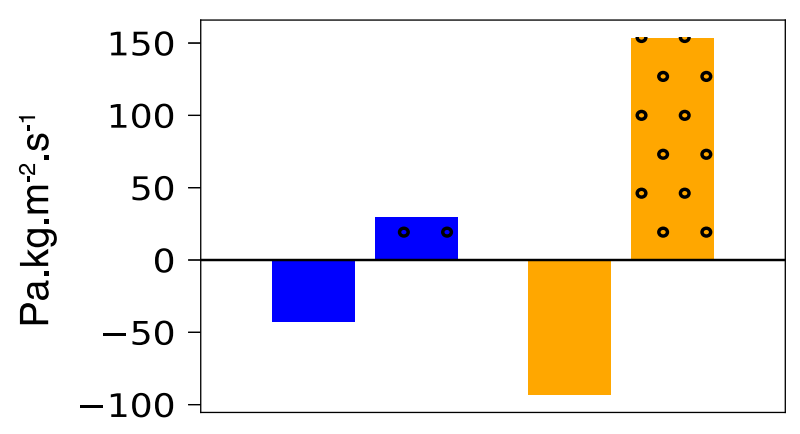

Ocean, GCM

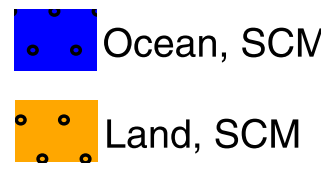

4xCO2 radiative-only with prescribed land

SST uniform $+4 K$

\section{Land, GCM}

FIG. 7. Annual-mean convective mass flux $M_{\text {INT }}$ (positive upward) response to different components of the $4 \times \mathrm{CO}_{2}$ forcing, in the GCM and from SCM runs. Each panel corresponds to two components of the forcing indicated in the panels' titles. Each shows GCM responses (plain bars) and corresponding SCM projections (circle-patterned bars) with fixed moisture coefficients (details hereafter), averaged over tropical $\left(20^{\circ} \mathrm{N}-20^{\circ} \mathrm{S}\right)$ ocean (blue bars) and land (orange bars). (a) GCM: AMIP_4xCO2rad_PL-AMIP_PL; SCM: [projection of SCM_4xCO2 on AMIP_4xCO2rad_PL, done using $T_{S}$ only and using the same $\beta$ and $q$ profile scaling as for the projection of SCM CTRL on AMIP_PL (see appendix B)]-[projection of SCM_CTRL on AMIP_PL (done using $T_{S}$ and $\mathrm{RH}_{S}$; see appendix B)]. (b) GCM: p4KSST-piSST; SCM: [projection of SCM_4K on p4KSST, done using $T_{S}$ only and using the same $\beta$ and $q$ profile scaling as for the projection of SCM_CTRL on piSST (see appendix B)]-projection of SCM_CTRL on piSST (done using $T_{S}$ and $\mathrm{RH}_{S}$; see appendix B).

by the SCM, as they involve local changes in radiative cooling.

Figure 7a shows the $M_{\text {INT }}$ response to the $4 \times \mathrm{CO}_{2}$ radiative-only direct effect, as simulated by the GCM and projected by the SCM, tropically averaged over ocean and over land. Here, we use the set of SCM experiments perturbed with increased atmospheric $\mathrm{CO}_{2}$ (SCM_4xCO2; see section 2c), based on a $4 \mathrm{xCO}_{2}$-perturbed environment. To investigate the direct response of the SCM vertical convective mass flux to the $4 \times \mathrm{CO}_{2}$ forcing, $\mathrm{RH}_{S}$ is left free to respond instead of being prescribed from the GCM (this is done by keeping the same scaling coefficients for evaporation and moisture as in the reference experiment; see appendix B; corresponding maps are given in Figs. S11a and S11b). Note that there are no $T_{S}$ changes anyway since the surface is prescribed over land and ocean. When increasing $\mathrm{CO}_{2}$, the SCM captures most of the convective mass flux weakening, as expected (Fig. 7a).

On average over land, the circulation weakening is a lot less pronounced than over the ocean in the GCM (Fig. 7a). This is because over most land regions except South America, circulation actually strengthens in response to the $4 \times \mathrm{CO}_{2}$ radiative-only forcing in the GCM (Fig. S11a). One possible explanation is that enhanced warming of the atmospheric column over desert regions reinforces monsoon circulations, by increasing land-ocean pressure gradients (Chadwick et al. 2019). This hypothesis is supported by the fact that the SCM does not capture any circulation strengthening over land (Fig. S11b), since it cannot reproduce such a direct atmospheric teleconnection that is not driven by surface warming.

\section{2) RAINFALL RESPONSE}

The rainfall response to the $4 \times \mathrm{CO}_{2}$ radiative-only forcing (Fig. 6i) is strongly consistent with the convective mass flux response mentioned above: rainfall decreases over the ocean following the tropical circulation weakening and increases over land, presumably because of enhanced monsoon systems associated with enhanced subtropical tropospheric warming. Over the ocean, the SCM only produces a very weak rainfall decrease over the southern Indian Ocean, the western Atlantic, and the western Pacific and no clear noticeable change over the central-eastern Pacific. This is consistent with the SCM not fully capturing the circulation weakening, as mentioned above. It is also due to $\mathrm{RH}_{S}$ changes over the ocean: in the GCM, $\mathrm{RH}_{S}$ is increased over the ocean by the weakened circulation (Fig. S8a), probably because of moisture building up near the surface; but in the SCM, increased $\mathrm{RH}_{S}$ tends to increase rainfall and counteract the rainfall reduction induced by the circulation weakening. Over land, the rainfall increase is captured by the $\mathrm{SCM}$, thanks to the associated $\mathrm{RH}_{S}$ increase (Fig. S8a).

\section{d. Uniform ocean warming}

\section{1) Circulation weakening}

Previous studies have shown that the overturning circulation is also weakened by global surface warming 
(Knutson and Manabe 1995; Ma et al. 2012; He et al. 2014; He and Soden 2015). This is consistent with reduced $M_{\text {INT }}$ across the whole tropics when a uniform $+4-\mathrm{K}$ ocean warming is applied in the GCM (Fig. 7b). This ocean warming-induced circulation weakening is thought to originate from increasing dry static stability $(\partial \theta / \partial z)$ in the descent regions (Knutson and Manabe 1995). When the surface warms by about $4 \mathrm{~K}$, the troposphere warms even more, as dictated by the shape of moist adiabat, which is maintained by convection in the tropics. This vertically nonuniform warming increases the dry static stability, which tends to increase dynamical heating $(w \partial \theta / \partial z)$. As dynamical heating and radiative cooling balance each other in descent regions, the limited increase in radiative cooling in descent regions limits the increase in dynamical heating and requires a reduction in the vertical motion $w$. By mass conservation, this weakens the whole overturning circulation. This process involves not only the direct local response to increased dry static stability, but also changes in mass transport that are not induced by local surface temperature, and are not captured by the WTG/DGW framework. Therefore, the SCM is not able to fully capture it.

Figure $7 \mathrm{~b}$ shows the $M_{\text {INT }}$ response to the uniform ocean $+4-\mathrm{K}$ warming, as simulated by the GCM and projected by the SCM tropically averaged over ocean and over land. Here, we use the set of SCM experiments perturbed with surface warming (SCM_4K; see section 2c), based on a $+4-\mathrm{K}$ perturbed environment (warmer and moister). To investigate the direct response of the SCM vertical circulation to the uniform ocean $+4-\mathrm{K}$ warming, $\mathrm{RH}_{S}$ is left free to respond instead of being prescribed from the GCM (this is done by keeping the same scaling coefficients for evaporation and moisture as in the reference experiment, see appendix B; corresponding maps are given in Fig. S11). When warming the surface (SCM_4K) as in p4KSST, the SCM does not produce any circulation weakening (Fig. 7b), even over the ocean. As mentioned above, explicit connections between ascent and descent regions are missing in the SCM, making it unable to fully capture the circulation weakening. The SCM only locally captures the weakening of subsidence in descent regions, as required by the local balance between dynamical heating and radiative cooling with increased dry static stability (Fig. S12). Therefore, our results support the above mechanism to explain the ocean warming-induced circulation weakening; that is the idea that it is not a direct local response to increased stability, but to changes in mass transport between ascent and descent regions that are independent from local surface changes.

Over land, the SCM predicts a strong increase in circulation instead of the strong decrease simulated by the GCM (Fig. 7b). A simple view to explain this result is that it follows enhanced land warming: with fixed moisture coefficients, the SCM DGW parameterization predicts that rainfall increases over land since land warms more than the ocean.

\section{2) RAINFALL RESPONSE}

In response to uniform ocean $+4-\mathrm{K}$ warming, precipitation generally increases over the ocean following the "wet get wetter" mechanism (Chou et al. 2009) as shown in Fig. 6k. The SCM produces a general rainfall increase over the ocean but strongly overestimates the magnitude (Fig. 61). This is consistent with the SCM not capturing the ocean warming-induced circulation weakening, as mentioned above, that damps the wet-getwetter response. Besides, our SCM setup is not able to represent the fact that as precipitation intensifies it can decrease on its margins due to enhanced advective drying (Chou et al. 2009).

As when perturbing SST patterns, ocean warming directly drives circulation changes over land (top-down forcing), which are thus not driven by the land surface (bottom-up forcing) and are not expected to be captured by the SCM. However, ocean warming also indirectly drives land surface warming, with land warming more than the ocean, associated with reduced $\mathrm{RH}_{S}$ (Sutton et al. 2007; Joshi et al. 2008; Dong et al. 2009; Lambert et al. 2011), as confirmed by Fig. S8d. Both enhanced land surface warming and reduced $\mathrm{RH}_{S}$ constitute a bottom-up forcing on the atmospheric column, which the SCM can capture. In the GCM, rainfall decreases over almost all tropical land in response to uniform ocean warming (Fig. 6k). Some studies suggest that this is caused by the decline of land $\mathrm{RH}_{S}$ (Fasullo 2012; Chadwick 2016; Lambert et al. 2017), in which case the land rainfall decrease would be a response to a bottomup forcing, reproducible in the SCM.

Other studies emphasize the role of remote tropospheric forcing on local rainfall and surface temperature changes (Chiang and Sobel 2002; Joshi et al. 2008; Giannini 2010). Following these ideas, the land rainfall decrease could be driven by a top-down forcing. For example, tropospheric warming over land (transmitted from the ocean by atmospheric waves, consistent with the WTG approximation) could directly suppress convection by stabilizing the column. Atmospheric stability over land cannot be fully diagnosed from the enhanced land warming, because of potential effects of both reduced $\mathrm{RH}_{S}$ and top-down atmospheric connections. Convection is already increased over the ocean, as a direct response to ocean warming; so it cannot be increased over land too, owing to mass and energy conservation. It can be viewed as the atmosphere over land being forced to import increased energy from the atmosphere over the ocean, as suggested by Lambert et al. (2011). Since radiative cooling over land can only increase by a limited 
amount, convection over land ultimately decreases to reduce latent heating and conserve energy. The SCM would not capture such a top-down atmospheric connection.

The SCM fails to capture the land rainfall decrease in response to uniform ocean warming (Fig. 61). Despite reduced land $\mathrm{RH}_{S}$, the SCM produces the opposite response, with a strong intensification of rainfall over land. This could indicate that the land rainfall decrease is not a response to the bottom-up forcing associated with reduced $\mathrm{RH}_{S}$; but to a top-down forcing, as proposed above. However, it could also simply be a result of the SCM precipitation being overly sensitive to surface temperatures, especially given the strong magnitude of the enhanced land surface warming in this case (not shown). As a result, it is possible that the effect of land surface warming dominates over the effect of reduced $\mathrm{RH}_{S}$ in the SCM, even if the opposite happens in the GCM. This means that it is possible that the SCM fails to capture a bottom-up forcing, which it is theoretically able to capture, because of its too-strong sensitivity to the surface temperature.

We cannot firmly determine the reasons for the SCM failure to reproduce the land rainfall decrease, but results are very consistent with Chadwick et al. (2019), who used two experiments isolating land warming only from ocean warming only. They showed that they did not add up linearly to the full ocean warming experiment, suggesting that forcing the atmosphere with land warming cannot capture the response of land rainfall to ocean warming.

\section{Conclusions}

This study uses a single-column model (SCM) representing the weak temperature gradient (WTG) approximation with the damped gravity wave (DGW) parameterization and implemented with moisture variations, in order to investigate: 1) how much of the present-day mean tropical rainfall and circulation pattern is associated with $T_{S}$ and $\mathrm{RH}_{S}$ patterns and 2) how much of the change in the mean tropical rainfall pattern is associated with the change in the tropical mean-state environment and in the $T_{S}$ and $\mathrm{RH}_{S}$ patterns.

Our first result is that most of the present-day mean tropical rainfall and circulation pattern is associated with $T_{S}$ and $\mathrm{RH}_{S}$ patterns, confirming the relevance of the WTG approximation. We use the SCM to produce a rainfall pattern that is associated with $T_{S}$ and $\mathrm{RH}_{S}$ patterns. We show that it captures much of the general circulation model (GCM) tropical mean rainfall pattern (correlation with HG3-AMIP of 0.71 over the entire tropics and 0.8 when considering only the ocean), although rainfall tends to extend too much spatially over the ocean. Previous studies have also found good correspondences between SCM and GCM rainfall (Sobel and Bretherton 2000; Zhu and Sobel 2012) but here we implement variations of moisture, which considerably improves the rainfall representation, especially over land. Despite the overall good correspondence, the SCM precipitation is too sensitive to the surface temperature compared with the GCM. This is probably associated with the lack of variability and transients in the simulated single column, which is specific to SCMs under the WTG approximation. As a result, the SCM overestimates rainfall on average. Rainfall over the ocean is too spatially extended and generally too strong, while regions with low rain rates are too dry. Land regions are too dry, except for some rain forests.

Our second result is that the change in the mean tropical rainfall pattern cannot be fully associated with the change in the tropical mean-state environment and in the $T_{S}$ and $\mathrm{RH}_{S}$ patterns. The SCM does not successfully reproduce the rainfall response to the full $\mathrm{CO}_{2}$ forcing. In particular, it fails to limit the increase in rainfall over the ocean and to reproduce the rainfall decrease over land that occurs when uniformly warming the ocean. This is, at least partly, because of the crucial role of circulation changes that are driven by remote surface changes through atmospheric teleconnections, highlighting the importance of top-down forcing (as opposed to bottom-up forcing). However, the too-strong sensitivity of the SCM precipitation to the surface temperature could also play a role in these misrepresentations.

By analyzing the differences between the SCM and the GCM, we were able to show that the weakening of the tropical atmospheric overturning circulation, which constrains rainfall changes, is only partly a direct local response to increasing $\mathrm{CO}_{2}$ : atmospheric teleconnections between ascent and descent regions, that are independent from local surface changes, play a crucial role. The tropical atmospheric overturning circulation weakens partly as a direct response to the increased atmospheric $\mathrm{CO}_{2}$ and partly in response to the subsequent tropics-wide surface warming. These two cases (the direct radiative-only effect of $4 \times \mathrm{CO}_{2}$ and the uniform ocean warming) are reproduced in the SCM using two different sets of perturbed SCM runs, based on a perturbed RCE environment (either with increased $\mathrm{CO}_{2}$ or with $+4-\mathrm{K}$ surface warming). The SCM captures most of the circulation weakening that is due to the direct radiative effect of increased $\mathrm{CO}_{2}$. However, it does not capture the circulation weakening that is due to the uniform surface warming. This suggests that it originates from static stability changes in descent regions, and also relies on atmospheric teleconnections between descent and ascent regions, that are independent from local surface changes (and not fully captured by the SCM). The fact that the SCM does not represent top-down atmospheric teleconnections, which seem to play a key 
role in weakening the overturning circulation, explains at least part of the misrepresentation of rainfall changes over the ocean (too much rainfall increase in response to ocean warming).

Even though the SCM does not successfully reproduce the full rainfall response to the $\mathrm{CO}_{2}$ forcing, it does successfully reproduce the rainfall response to changes in the SST pattern only. We show that the rainfall response to changes in the SST pattern, which is the dominant part of the full rainfall change over the ocean, can be mostly associated with large-scale circulation changes driven by $T_{S}$ and $\mathrm{RH}_{S}$ patterns, suggesting a dominant role for the local effect of SST pattern change on convective instability (rather than the influence of SST gradients on boundary layer pressure gradients).

The rainfall response to vegetation changes caused by the $\mathrm{CO}_{2}$ increase, which are a dominant component of rainfall changes over tropical forest regions (Betts et al. 2004; Cao et al. 2012; Chadwick et al. 2017), can also be mostly associated with $T_{S}$ and $\mathrm{RH}_{S}$ pattern changes. The SCM successfully reproduces the rainfall response to vegetation changes caused by the $\mathrm{CO}_{2}$ increase. It reproduces rainfall increases over land when forced by land warming, rainfall decreases when forced by evaporation weakening, and even some of the Amazon drying that appears in response to land warming induced by vegetation changes. These results are reassuring, as they suggest that rainfall changes can be well diagnosed from changes in $T_{S}$ and $\mathrm{RH}_{S}$, when they are forced by perturbations in surface temperature and evaporation patterns. However, when the forcing is applied over land, the SCM does not capture rainfall changes over the ocean or over some land regions. This suggests that changes in the local surface temperature and evaporation do not dominate regional rainfall changes over land everywhere. Remotely driven changes in low-level wind convergence, independent from local surface changes, can play a crucial role in some tropical land regions.

We cannot exclude the possibility that our SCM setup, as a simplified representation of the WTG approximation, using an idealized parameterization in a one-dimensional model, biases our results, due to misrepresenting the sensitivity of rainfall to temperature and humidity. The goal of this study was not to perfectly reproduce the mean tropical rainfall pattern and its response to climate change, but to diagnose its drivers and better understand it. Further work is needed to confirm or disprove our hypotheses. To better represent land regions, the SCM could be coupled to a land surface model. To test our hypothesis on land precipitation decreases, another setup could be used by connecting a second column to the existing one, which would not be forced at the surface but coupled to a land surface model. Finally, our analyses could be replicated using GCM experiments performed with HadGEM3, the SCM's parent GCM, once they are available. Even though circulation weakening, for example, is a quite robust climate change response across models, this would give more confidence on the attribution of the differences between the SCM and the GCM results for climate change.

Acknowledgments. The authors thank Adam Sobel and the two other anonymous reviewers for their comments and suggestions, which helped to substantially improve the quality of the manuscript. The authors thank Duncan Ackerley for producing of the prescribedland ACCESS simulations, and Peter Good, Hongyan Zhu, Christopher Holloway, and Adam Sobel again for helpful advice and discussions. The ACCESS simulations were undertaken with the assistance of the resources from the National Computational Infrastructure (NCI), which is supported by the Australian Government. Data are publicly available from the NCI. Input surface temperature, soil moisture, and deep soil temperatures are also available from the NCI upon request. The relevant doi (and other metadata) for each of the individual experiments can be found in the supporting information attached to Ackerley et al. (2018). The authors thank the JASMIN and CEDA team for making available the JASMIN computing resource Lawrence et al. (2013). This work was supported by the U.K. Natural Environment Research Council, Grant NE/N018486/1. Rob Chadwick was supported by the Newton Fund through the Met Office Climate Science for Service Partnership Brazil (CSSP Brazil).

\section{APPENDIX A}

\section{Mathematical Formulation of the Damped Gravity Wave Parameterization and Horizontal Advection Schemes in the SCM}

\section{a. Damped gravity wave parameterization}

The DGW parameterization consists in providing a solution to the system of momentum, continuity, and hydrostatic equations that maintains weak free-tropospheric temperature gradients.

Our formulation of the DGW parameterization follows Kuang (2008), is described in Daleu et al. (2015), and is summarized in this section.

Considering the decomposition of a variable $X$ into a mean-equilibrated value $\bar{X}$ and a perturbation $X^{\prime}$, the 2D linearized perturbed equations of momentum, continuity, and hydrostatic balance can be written as 


$$
\begin{aligned}
\bar{\rho} \partial_{t} u^{\prime} & =-\partial_{x} p^{\prime}-\epsilon \bar{\rho} u^{\prime}, \\
\partial_{x}\left(\bar{\rho} u^{\prime}\right)+\partial_{z}\left(\bar{\rho} w^{\prime}\right) & =0, \quad \text { and } \\
\partial_{z} p^{\prime} & =\bar{\rho} g \frac{T_{v}^{\prime}}{\overline{T_{v}}}
\end{aligned}
$$

where $\epsilon$ is the mechanical damping of 1 day $^{-1}$.

This system is solved by assuming a solution in the form $T^{\prime}=\operatorname{Re}\left(\hat{T} e^{-i k x}\right)$, describing the temperature perturbation $T^{\prime}$ as vanishing with horizontal distance. This solution represents the horizontal propagation of a gravity wave of a single wavenumber $k=10^{-6} \mathrm{~m}^{-1}$ that maintains horizontal uniformity. We performed a few SCM runs using $k=2 \times 10^{-6} \mathrm{~m}^{-1}$ (another value used in the literature): it does not make any noticeable difference (not shown).

In steady state, injecting this solution in the system yields

$$
\rho^{\mathrm{ref}} w^{\prime}=\int_{z} \int_{z}-\frac{k^{2}}{\varepsilon} \frac{\rho^{\mathrm{ref}} g}{T_{v}^{\mathrm{ref}}} T_{v}^{\prime} d z^{2}
$$

In this framework, the vertical motion $w^{\prime}$ responds to temperature perturbations - which horizontally vanish with respects to the WTG approximation-by keeping hydrostatic equilibrium, continuity, and momentum conservation.

\section{b. Moisture advection}

We parameterize the horizontal advection of moisture from the environment into the simulated column. We define two terms of advection. The first one is the lateral drawing, describing the horizontal advection of moisture by the locally parameterized circulation. The second one is the moisture relaxation, representing the horizontal mixing of moisture through the mean rotational flow and transient eddies, unrelated to the circulation parameterized in the column. We argue they represent different processes and can be used together.

\section{1) LATERAL DRAWING}

Following Daleu et al. (2015), horizontal advection of moisture induced by the vertical motion is defined as the drawing of the reference air into the simulated domain, at each vertical level:

$$
\left(\frac{\partial q}{\partial t}\right)_{\text {drawing }}=\max \left(\frac{\partial \omega}{\partial p}, 0\right)\left(q^{\mathrm{ref}}-q\right),
$$

where $\max \left(\partial_{p} \omega, 0\right)$ is nonzero only if there is convergence into the simulated column.

\section{2) HORIZONTAL MIXING}

Zhu and Sobel (2012) showed that the sensitivity of rainfall to surface temperature was better represented by relaxing the moisture profile toward the environment. By representing horizontal mixing, this moisture relaxation scheme prevents the simulated domain from getting unrealistically different from its environment.

We implement the following moisture relaxation scheme in our SCM:

$$
\left(\frac{\partial q}{\partial t}\right)_{\text {mixing }}=\frac{q_{\text {ref }}-q}{\tau_{q}}
$$

where $\tau_{q}$ is the relaxation time scale that we fix to 1 day. In annual mean, tropical surface waters can remain at approximately the same temperature $( \pm 0.2 \mathrm{~K})$ over a distance on the order of $500 \mathrm{~km}$ (not shown). In the SCM, surface winds are fixed at $5 \mathrm{~ms}^{-1}$. It would take about 1.15 days for moisture to be transported by a mean flow of $5 \mathrm{~m} \mathrm{~s}^{-1}$ over $500 \mathrm{~km}$. A time scale of 1 day would then be typical of horizontal moisture mixing between the simulated domain and a surrounding environment that is far enough to be independent of the former (i.e., not under the same regime).

\section{APPENDIX B}

\section{Methods for the Projection of SCM Results on a Map}

To project a set of SCM runs (SCM_CTRL, SCM $4 \mathrm{xCO}$, or SCM_4K) on the climatology of a GCM experiment, we consider the GCM surface temperatures $\left(T_{S}\right)$ anomalies to the tropical average SST (on $20^{\circ} \mathrm{N}-$ $20^{\circ} \mathrm{S}$ ), and the SCM $T_{S}$ anomalies to $T_{s}^{\mathrm{RCE}}$. In most cases, we will also consider GCM and SCM near-surface relative humidity values $\left(\mathrm{RH}_{S}\right)$. SCM results, $T_{S}$ and $\mathrm{RH}_{S}$, are always time means over the last 40 days of the run. Projections are all performed on every month of the mean annual cycle of the GCM climatology, and then averaged over the year to obtain the annual-mean projection.

- Projection using GCM $T_{S}$ (Fig. 3b): on each grid point, the SCM run that has the closest $T_{S}$ anomaly is projected.

- Projection using GCM $T_{S}$ and $\mathrm{RH}_{S}$ (Figs. 3c and $6 \mathrm{~b}, \mathrm{~d}, \mathrm{~h}, \mathrm{j}, \mathrm{l})$ : on each grid point, the SCM run that has the closest $T_{S}$ anomaly and $\mathrm{RH}_{S}$ is projected.

- Projection using GCM $T_{S}$, and using the same $\beta$ and $q$ profile scaling as for a reference projection, that is, allowing no change in moisture coefficients (Fig. 7): on a reference projection, of a given set of SCM runs (SCM_REF) on $T_{S}$ and $\mathrm{RH}_{S}$ from a given GCM experiment (GCM_REF), one particular SCM run, which was performed using a unique combination of 
( $T_{S}, \beta, q$ profile scaling), is projected on one particular month and grid point of GCM_REF. Thus, each grid point of each month is associated with one value of $\beta$ $\left(\beta_{\text {ref }}\right)$ and one $q$ profile scaling $\left(q_{-}\right.$scaling $\left._{\text {ref }}\right)$, which can be stored. The new projection of a set of SCM runs (SCM_PERT) on another GCM experiment (GCM_ PERT) is then performed doing the following: on each grid point, the SCM_PERT run that has the closest $T_{S}$ anomaly and was performed using $\beta_{\text {ref }}$ and $q_{-}$scaling ref is projected (i.e., the same $\beta$ and $q$ profile scaling as the SCM_REF run projected on that same month and on that same grid point of GCM_REF).

- Projection using GCM $T_{S}$ and $\mathrm{RH}_{S}$, and using the same $q$ profile scaling as for another projection (Fig. 6f): the projection of a set of SCM runs (SCM_PERT) on a GCM experiment (GCM_PERT) is performed doing the following. On each grid point, the SCM_PERT run that has the closest $T_{S}$ anomaly and $\mathrm{RH}_{S}$, and that was performed using $q_{-}$scaling ref $_{\text {, }}$ is projected (i.e., the same $q$ profile scaling as the SCM_REF run projected on that same month and on that same grid point of GCM_ $\mathrm{REF})$. Only $\beta$ is allowed to be different.

The conditions for projection on each grid point, when applicable, are that the SCM and the gridpoint $T_{S}$ and $\mathrm{RH}_{S}$ are not different by more than the spatiotemporal standard deviation of the GCM $T_{S}$ and $\mathrm{RH}_{S}$, respectively (standard deviation of the flattened 12 months $\times$ latitudes $\times$ longitudes array). As a result, it is possible that nothing projects on the grid point.

\section{REFERENCES}

Ackerley, D., and D. Dommenget, 2016: Atmosphere-only GCM (ACCESS1.0) simulations with prescribed land surface temperatures. Geosci. Model Dev., 9, 2077-2098, https://doi.org/ 10.5194/gmd-9-2077-2016.

— , R. Chadwick, D. Dommenget, and P. Petrelli, 2018: An ensemble of AMIP simulations with prescribed land surface temperatures. Geosci. Model Dev., 11, 3865-3881, https:// doi.org/10.5194/gmd-11-3865-2018.

Anber, U., P. Gentine, S. Wang, and A. H. Sobel, 2015: Fog and rain in the Amazon. Proc. Natl. Acad. Sci. USA, 112, 11473 11477, https://doi.org/10.1073/pnas.1505077112.

Back, L. E., and C. S. Bretherton, 2009: On the relationship between SST gradients, boundary layer winds, and convergence over the tropical oceans. J. Climate, 22, 4182-4196, https:// doi.org/10.1175/2009JCLI2392.1.

Bergman, J. W., and P. D. Sardeshmukh, 2004: Dynamic stabilization of atmospheric single column models. J. Climate, 17, 1004-1021, https://doi.org/10.1175/1520-0442(2004)017<1004: DSOASC $>2.0 . \mathrm{CO} ; 2$.

Betts, R. A., P. M. Cox, M. Collins, P. P. Harris, C. Huntingford, and C. D. Jones, 2004: The role of ecosystem-atmosphere interactions in simulated Amazonian precipitation decrease and forest dieback under global climate warming. Theor. Appl. Climatol., 78, 157-175, https://doi.org/10.1007/S00704-004-0050-y.
Bi, D., and Coauthors, 2013: The ACCESS coupled model: Description, control climate and evaluation. Aust. Meteor. Oceanogr. J., 63, 41-64, https://doi.org/10.22499/2.6301.004.

Bony, S., G. Bellon, D. Klocke, S. Sherwood, S. Fermepin, and S. Denvil, 2013: Robust direct effect of carbon dioxide on tropical circulation and regional precipitation. Nat. Geosci., 6 , 447-451, https://doi.org/10.1038/ngeo1799.

Byrne, M. P., and P. A. O'Gorman, 2016: Understanding decreases in land relative humidity with global warming: Conceptual model and GCM simulations. J. Climate, 29, 9045-9061, https://doi.org/10.1175/JCLI-D-16-0351.1.

Cao, L., G. Bala, and K. Caldeira, 2012: Climate response to changes in atmospheric carbon dioxide and solar irradiance on the time scale of days to weeks. Environ. Res. Lett., 7, 034015 , https://doi.org/10.1088/1748-9326/7/3/034015.

Chadwick, R., 2016: Which aspects of $\mathrm{CO}_{2}$ forcing and SST warming cause most uncertainty in projections of tropical rainfall change over land and ocean? J. Climate, 29, 2493-2509, https://doi.org/10.1175/JCLI-D-15-0777.1.

, I. Boutle, and G. Martin, 2013: Spatial patterns of precipitation change in CMIP5: Why the rich do not get richer in the tropics. J. Climate, 26, 3803-3822, https://doi.org/10.1175/ JCLI-D-12-00543.1.

— , P. Good, T. Andrews, and G. Martin, 2014: Surface warming patterns drive tropical rainfall pattern responses to $\mathrm{CO}_{2}$ forcing on all timescales. Geophys. Res. Lett., 41, 610-615, https://doi.org/10.1002/2013GL058504.

$\longrightarrow,-$, and K. Willett, 2016: A simple moisture advection model of specific humidity change over land in response to SST warming. J. Climate, 29, 7613-7632, https://doi.org/10.1175/ JCLI-D-16-0241.1.

$\longrightarrow$, H. Douville, and C. B. Skinner, 2017: Timeslice experiments for understanding regional climate projections: Applications to the tropical hydrological cycle and European winter circulation. Climate Dyn., 49, 3011-3029, https://doi.org/10.1007/ S00382-016-3488-6.

— D. Ackerley, T. Ogura, and D. Dommenget, 2019: Separating the influences of land warming, the direct $\mathrm{CO}_{2}$ effect, the plant physiological effect, and SST warming on regional precipitation changes. J. Geophys. Res. Atmos., 124, 624-640, https:// doi.org/10.1029/2018JD029423.

Chiang, J. C. H., and A. H. Sobel, 2002: Tropical tropospheric temperature variations caused by ENSO and their influence on the remote tropical climate. J. Climate, 15, 2616-2631, https://doi.org/ 10.1175/1520-0442(2002)015<2616:TTTVCB $>2.0$.CO;2.

- S. E. Zebiak, and M. A. Cane, 2001: Relative roles of elevated heating and surface temperature gradients in driving anomalous surface winds over tropical oceans. J. Atmos. Sci., 58, 1371-1394, https://doi.org/10.1175/1520-0469(2001)058<1371: RROEHA $>2.0 . \mathrm{CO} ; 2$.

Chou, C., J. D. Neelin, C.-A. Chen, and J.-Y. Tu, 2009: Evaluating the "rich-get-richer" mechanism in tropical precipitation change under global warming. J. Climate, 22, 1982-2005, https://doi.org/10.1175/2008JCLI2471.1.

Collins, M., and Coauthors, 2013: Long-term climate change: Projections, commitments and irreversibility. Climate Change 2013: The Physical Science Basis, T. F. Stocker et al., Eds., Cambridge University Press, 1029-1136.

Cox, P. M., R. A. Betts, C. B. Bunton, R. L. H. Essery, P. R. Rowntree, and J. Smith, 1999: The impact of new land surface physics on the GCM simulation of climate and climate sensitivity. Climate Dyn., 15, 183-203, https://doi.org/10.1007/S003820050276. 
Daleu, C. L., and Coauthors, 2015: Intercomparison of methods of coupling between convection and large-scale circulation: 1. Comparison over uniform surface conditions. J. $A d v$. Model. Earth Syst., 7, 1576-1601, https://doi.org/10.1002/ 2015MS000468.

Diakhaté, M., A. Lazar, G. Coëtlogon, and A. T. Gaye, 2018: Do SST gradients drive the monthly climatological surface wind convergence over the tropical Atlantic? Int. J. Climatol., 38 (S1), e955-e965, https://doi.org/10.1002/joc.5422.

Dong, B., J. M. Gregory, and R. T. Sutton, 2009: Understanding land-sea warming contrast in response to increasing greenhouse gases. Part I: Transient adjustment. J. Climate, 22, 30793097, https://doi.org/10.1175/2009JCLI2652.1.

Fasullo, J., 2012: A mechanism for land-ocean contrasts in global monsoon trends in a warming climate. Climate Dyn., 39, 11371147, https://doi.org/10.1007/S00382-011-1270-3.

Giannini, A., 2010: Mechanisms of climate change in the semiarid African Sahel: The local view. J. Climate, 23, 743-756, https:// doi.org/10.1175/2009JCLI3123.1.

He, J., and B. J. Soden, 2015: Anthropogenic weakening of the tropical circulation: The relative roles of direct $\mathrm{CO}_{2}$ forcing and sea surface temperature change. J. Climate, 28, 8728-8742, https://doi.org/10.1175/JCLI-D-15-0205.1.

- - , and B. Kirtman, 2014: The robustness of the atmospheric circulation and precipitation response to future anthropogenic surface warming. Geophys. Res. Lett., 41, 26142622, https://doi.org/10.1002/2014GL059435.

Held, I. M., and B. J. Soden, 2006: Robust responses of the hydrological cycle to global warming. J. Climate, 19, 5686-5699, https://doi.org/10.1175/JCLI3990.1.

Joshi, M. M., J. M. Gregory, M. J. Webb, D. M. H. Sexton, and T. C. Johns, 2008: Mechanisms for the land/sea warming contrast exhibited by simulations of climate change. Climate Dyn., 30, 455-465, https://doi.org/10.1007/s00382-007-0306-1.

Kent, C., R. Chadwick, and D. P. Rowell, 2015: Understanding uncertainties in future projections of seasonal tropical precipitation. J. Climate, 28, 4390-4413, https://doi.org/10.1175/ JCLI-D-14-00613.1.

Knutson, T. R., and S. Manabe, 1995: Time-mean response over the tropical Pacific to increased $\mathrm{CO}_{2}$ in a coupled ocean-atmosphere model. J. Climate, 8, 2181-2199, https://doi.org/10.1175/15200442(1995)008<2181:TMROTT>2.0.CO;2.

Knutti, R., and J. Sedláček, 2013: Robustness and uncertainties in the new CMIP5 climate model projections. Nat. Climate Change, 3, 369-373, https://doi.org/10.1038/nclimate1716.

Kuang, Z., 2008: Modeling the interaction between cumulus convection and linear gravity waves using a limited-domain cloud system-resolving model. J. Atmos. Sci., 65, 576-591, https:// doi.org/10.1175/2007JAS2399.1.

, 2011: The wavelength dependence of the gross moist stability and the scale selection in the instability of column-integrated moist static energy. J. Atmos. Sci., 68, 61-74, https://doi.org/ 10.1175/2010JAS3591.1.

Lambert, F. H., M. J. Webb, and M. M. Joshi, 2011: The relationship between land-ocean surface temperature contrast and radiative forcing. J. Climate, 24, 3239-3256, https://doi.org/ 10.1175/2011JCLI3893.1.

_ A. J. Ferraro, and R. Chadwick, 2017: Land-ocean shifts in tropical precipitation linked to surface temperature and humidity change. J. Climate, 30, 4527-4545, https://doi.org/ 10.1175/JCLI-D-16-0649.1.

Lawrence, B. N., and Coauthors, 2013: Storing and manipulating environmental big data with JASMIN. Proc. 2013 IEEE Int.
Conf. on Big Data, Silicon Valley, CA, IEEE Big Data, 68-75, https://doi.org/10.1109/BigData.2013.6691556.

Lindzen, R. S., and S. Nigam, 1987: On the role of sea surface temperature gradients in forcing low-level winds and convergence in the tropics. J. Atmos. Sci., 44, 2418-2436, https://doi.org/ 10.1175/1520-0469(1987)044<2418:OTROSS >2.0.CO;2.

Long, S.-M., S.-P. Xie, and W. Liu, 2016: Uncertainty in tropical rainfall projections: Atmospheric circulation effect and the ocean coupling. J. Climate, 29, 2671-2687, https://doi.org/ 10.1175/JCLI-D-15-0601.1.

Ma, J., and S.-P. Xie, 2013: Regional patterns of sea surface temperature change: A source of uncertainty in future projections of precipitation and atmospheric circulation. J. Climate, 26, 2482-2501, https://doi.org/10.1175/JCLI-D-12-00283.1.

— _ _ a and Y. Kosaka, 2012: Mechanisms for tropical tropospheric circulation change in response to global warming. J. Climate, $\mathbf{2 5}$ 2979-2994, https://doi.org/10.1175/JCLI-D-11-00048.1.

Martin, G. M., and Coauthors, 2011: The HadGEM2 family of Met Office Unified Model climate configurations. Geosci. Model Dev., 4, 723-757, https://doi.org/10.5194/gmd-4-723-2011.

Merlis, T. M., 2015: Direct weakening of tropical circulations from masked $\mathrm{CO}_{2}$ radiative forcing. Proc. Natl. Acad. Sci. USA, 112, 13 167-13 171, https://doi.org/10.1073/pnas.1508268112.

O'Gorman, P. A., and C. J. Muller, 2010: How closely do changes in surface and column water vapor follow ClausiusClapeyron scaling in climate change simulations? Environ. Res. Lett., 5, 025207, https://doi.org/10.1088/1748-9326/5/2/ 025207.

Oueslati, B., S. Bony, C. Risi, and J.-L. Dufresne, 2016: Interpreting the inter-model spread in regional precipitation projections in the tropics: Role of surface evaporation and cloud radiative effects. Climate Dyn., 47, 2801-2815, https://doi.org/10.1007/ s00382-016-2998-6.

Saint-Lu, M., R. Chadwick, F. H. Lambert, and M. Collins, 2019: Surface warming and atmospheric circulation dominate rainfall changes over tropical rainforests under global warming. Geophys. Res. Lett., 46, 13 410-13 419, https://doi.org/10.1029/ 2019GL085295.

Sellers, P. J., and Coauthors, 1996: Comparison of radiative and physiological effects of doubled atmospheric $\mathrm{CO}_{2}$ on climate. Science, 271, 1402-1406, https://doi.org/10.1126/science.271.5254.1402.

Shepherd, T. G., 2014: Atmospheric circulation as a source of uncertainty in climate change projections. Nat. Geosci., 7, 703708, https://doi.org/10.1038/ngeo2253.

Simmons, A. J., K. M. Willett, P. D. Jones, P. W. Thorne, and D. P. Dee, 2010: Low-frequency variations in surface atmospheric humidity, temperature, and precipitation: Inferences from reanalyses and monthly gridded observational data sets. J. Geophys. Res., 115, D01110, https://doi.org/10.1029/ 2009JD012442.

Sobel, A. H., and C. S. Bretherton, 2000: Modeling tropical precipitation in a single column. J. Climate, 13, 4378-4392, https:// doi.org/10.1175/1520-0442(2000)013<4378:MTPIAS >2.0.CO;2.

— , and G. Bellon, 2009: The effect of imposed drying on parameterized deep convection. J. Atmos. Sci., 66, 2085-2096, https://doi.org/10.1175/2008JAS2926.1.

_ - J. Nilsson, and L. M. Polvani, 2001: The weak temperature gradient approximation and balanced tropical moisture waves J. Atmos. Sci., 58, 3650-3665, https://doi.org/10.1175/15200469(2001)058<3650:TWTGAA > 2.0.CO;2.

— G. Bellon, and J. Bacmeister, 2007: Multiple equilibria in a single-column model of the tropical atmosphere. Geophys. Res. Lett., 34, L22804, https://doi.org/10.1029/2007GL031320. 
Sutton, R. T., B. Dong, and J. M. Gregory, 2007: Land/sea warming ratio in response to climate change: IPCC AR4 model results and comparison with observations. Geophys. Res. Lett., 34, L02701, https://doi.org/10.1029/2006GL028164.

Todd, A., M. Collins, F. H. Lambert, and R. Chadwick, 2018: Diagnosing ENSO and global warming tropical precipitation shifts using surface relative humidity and temperature. J. Climate, 31, 1413-1433, https://doi.org/10.1175/JCLI-D-17-0354.1.

Vecchi, G. A., and B. J. Soden, 2007: Global warming and the weakening of the tropical circulation. J. Climate, 20, 43164340, https://doi.org/10.1175/JCLI4258.1.

Walters, D., and Coauthors, 2019: The Met Office Unified Model Global Atmosphere 7.0/7.1 and JULES Global Land 7.0 configurations. Geosci. Model Dev., 12, 1909-1963, https:// doi.org/10.5194/gmd-12-1909-2019.

Wang, S., A. H. Sobel, and Z. Kuang, 2013: Cloud-resolving simulation of TOGA-COARE using parameterized large-scale dynamics. J. Geophys. Res. Atmos., 118, 6290-6301, https:// doi.org/10.1002/JGRD.50510.

Xie, S.-P., C. Deser, G. A. Vecchi, J. Ma, H. Teng, and A. T. Wittenberg, 2010: Global warming pattern formation: Sea surface temperature and rainfall. J. Climate, 23, 966-986, https://doi.org/10.1175/2009JCLI3329.1.

Zhu, H., and A. H. Sobel, 2012: Comparison of a single-column model in weak temperature gradient mode to its parent AGCM. Quart. J. Roy. Meteor. Soc., 138, 1025-1034, https://doi.org/10.1002/qj.967. 